\title{
Financing the Reconstruction of Public Capital after a Natural Disaster*
}

\author{
David Bevan
}

david.bevan@sjc.ox.ac.uk

and

Christopher Adam

christopher.adam@economics.ox.ac.uk

University of Oxford, UK

Keywords: natural disasters, public capital reconstruction, public finance, macro-modelling JEL Codes: H54, Q54, E60

${ }^{*}$ This paper is a product of the Disaster Risk Financing and Insurance Program (DRFIP), a partnership of the World Bank's Finance and Markets Global Practice Group and the Global Facility for Disaster Reduction and Recovery, with funding from the UK Department for International Development. It is part of a larger effort by the World Bank to provide open access to its research and make a contribution to development policy discussions around the world. Policy Research Working Papers are also posted on the Web at http://econ.worldbank.org. We are particularly grateful to Daniel Clarke and Richard Poulter for their advice and guidance, and we thank Samantha Cook, Stephen Hallegatte, Alejandro Guerson and Wendell Samuel for comments on an earlier draft of this paper. We thank Radhika Goyal for excellent research assistance at the early stages of this project. 


\section{Introduction}

When natural disasters strike, attention tends to focus on the loss of lives and livelihoods, the loss of output and the destruction of private dwellings and factories. Public policy responses will often prioritize the securing of basic livelihoods in the short run and consider how private capital is restored over the medium term. But natural disasters do not discriminate and are liable to destroy public infrastructure capital just as readily as they do private capital. The key feature of public capital is that it is complementary to private factors of production; the destruction of public capital, therefore, not only lowers current private output but also lowers the ex ante return to private capital and labor, so that the loss of public capital blunts the private sector's incentives to rebuild. Both effects are magnified the more important are the network properties of public capital. By the same token, the speed with which the public capital stock is restored post-disaster plays a decisive role in determining the recovery in private output and consumption. The speed of rebuild is only one element of the reconstruction, however. The other is how reconstruction is financed. In practice, small disaster-prone countries may find it difficult to access external debt markets in the wake of natural disasters, which means that unless development assistance (in the form of donor grants) is forthcoming, the choice reduces to three options. The first is to rely on domestic financing. This may involve some level of domestic debt financing in the short-run, but ultimately it means relying on domestic taxation, the impact of which depends on how distortionary the tax system is. The second option is to finance reconstruction by re-allocating public expenditure from other uses, including from the operations and maintenance expenditures on the surviving public capital stock. The third option is for the country to take out disaster risk insurance. With insurance in place, the direct costs of the rebuild are met without the need to raise taxes or reallocate expenditures. In addition, market-based insurance may be bundled with forms of technical expertise so that the rebuild rate can be faster than when tax-financed. Against this must be set the cost of carrying insurance which needs to be financed from the (distortionary) domestic tax system.

In this paper we examine the consequences of natural disasters and the post-disaster reconstruction of public capital for the macroeconomic dynamics of a small open economy, and how these may be modified when government has access to disaster risk insurance. We first construct a dynamic general equilibrium model capable of describing the dynamic adjustment of an economy following a natural disaster, and then implement a 'quasi-Monte Carlo' numerical simulation approach to examine the behavior of the model economy under a small range of policy settings in the face of a set of draws from an empirical distribution of disasters. The model we develop is calibrated to recent national accounts data for Jamaica and combined with a recent natural disaster risk profile developed for the country. To focus on the principal mechanisms of interest, as well as to keep the analysis manageable, we limit our attention to the specific risks posed by tropical cyclones and assume that the destruction brought about is 
entirely concentrated on the public infrastructure capital stock. There is no direct destruction of the private capital stock, either residential or commercial, nor are any lives or indeed any current output lost as a result of this hazard. The entire impact on private output and consumption comes solely through the loss of complementary public infrastructure capital. For example, we may think of this hypothetical cyclone destroying roads or key bridges, port infrastructure, or bringing down power transmission lines. Within this modeling framework, it would, of course, be straightforward to model the disaster in a more complex manner, allowing for direct destruction of private capital as well as for other temporary interruptions to current production. However, the purpose of the paper is to illustrate how this modeling framework can be used to think about the dynamics of destruction and reconstruction and of the role of disaster risk insurance; we believe that the characterization used here is sufficient to identify the key considerations relevant to doing so.

The remainder of the paper is as follows. Section 2 describes the basic structure of the general equilibrium model, with more detail being provided in the Appendix. Section 3 shows how the profile of natural disasters that confronts the economy is characterized. Ideally, this profile would be described by a continuous distribution, and a full-blown Monte Carlo simulation would take a large number of draws from this distribution, then feed these into the model. This is impractical, given the complexity of the model, and the impracticality - and perhaps undesirability - of endogenizing all the policy responses. The section spells out a simpler approach which seems to be reasonably well related to this ideal. Section 4 then discusses a range of policy responses to these risks, and ways of formulating counterfactuals to these responses. These responses include four cases, of which three involve a proactive response: in the first of these, the public investment re-financing program has to be entirely tax-financed; in the second, it is financed entirely by budget reallocation, specifically from the O\&M component of the budget; in the third, disaster risk insurance is in place 1 These three active responses are contrasted with a "do nothing" approach under which reconstruction takes place more slowly without recourse to additional finance. Under realistic assumptions, reconstruction is more rapid with insurance in place and is achieved with higher private consumption and lower domestic taxation than would otherwise be the case. But high-damage hurricanes are rare events and so whether it is worthwhile taking out insurance depends on the nature of the insurance contract, the economic consequences of the loss of public capital and the expected frequency of high-damage events. Insurers typically charge a high premium, so that insurance is not actuarially fair. In Section 5, we describe the results to the corresponding simulations, and examine the expected welfare payoff to these different responses. There is a range of metrics available to us in computing what response is best, and whether insurance is worthwhile. These include discounted and undiscounted utilities, but for transparency we have opted to use the annuitized change in private consumption. Besides the

\footnotetext{
${ }^{1}$ All the simulations examine the case where the disaster occurs (if at all) in the first year, and there is no repeat event within the simulated horizon.
} 
advantage of being easily understood, it turns out that the qualitative conclusions are insensitive to the metric adopted. We also report internal rates of return to more rapid reconstruction and the opportunity costs of different financing mechanisms. The broad conclusion of these exercises is that whether the advantages of insurance - notably a more rapid rebuild - are sufficient to justify paying the high premium that insurers demand is moot, depending on the details of the case. Section 6 concludes with some implications for policy, including the possible use of this modeling approach to generate numbers that can be used in simpler models that can be more easily applied in a policy context.

\section{The Model}

Our model is an adaptation of one developed recently by the IMF Research Department and subsequently modified to improve its public finance attributes.2 2 The broad characteristics of the model are described in our interim paper (Bevan and Adam, 2014) and the principal equations of the model are listed in Appendix I.

The model is of a small open economy model, with two sectors, tradables and non-tradables. It is a real model with no nominal assets, no nominal rigidities and hence no role for monetary policy. Production in each sector is a function of public and private capital and of labor, and is carried out by competitive, price-taking firms. There are constant returns to the private factors, and increasing returns to all three factors taken together. There is steady trend growth in productivity, uniform across sectors. Public debt may be domestic, external concessional, or external non-concessional. Interest payable on the last of these may include a risk premium that rises with the government's indebtedness. Some households have access to financial markets, while others are credit constrained and consume their current income. The former maximize an additive intertemporal utility function; for all households, instantaneous utility is a function of both consumption and leisure.

Taxes are levied on capital and labor incomes (at a common rate) and on consumption. Given the characterization of firms and households, these taxes are distortionary and impose deadweight losses on the private sector; getting a dollar into the hands of the government inflicts more than a dollar of cost on the private sector. In addition, not all of the revenue that a given tax rate would raise, given the tax base, actually accrues to government as spendable resources. This leakage may reflect a range of things, including the costs of tax administration, the existence of tax exemptions, tax avoidance and tax evasion, and indeed some degree of corruption. Taxes are used to make transfers to citizens, to service debt, and to finance public investment.

A conventional specification of complementarity defines production in each sector as

$$
q_{j, t}=a_{j}\left(z_{t-1}\right)^{\psi_{j}}\left(k_{j, t-1}\right)^{\alpha_{j}}\left(L_{j, t}\right)^{1-\alpha_{j}}
$$

\footnotetext{
${ }^{2}$ Buffie et al (2012) and Adam and Bevan (2014).
} 
where $z_{t-1}$ is public capital and $\psi_{j}>0$ measures the extent of increasing returns generated by public infrastructure. To reflect the network nature of public capital we modify this conventional treatment of the complementarity of public and private capital in two ways. First, it is assumed that there is a threshold effect for public capital, embodied in $\bar{z}$, before it becomes productive. One could think of a network, such as a road system, where odd bits of road make very little contribution to output, but a connected system does. This modifies 2.1 to:

$$
q_{j, t}=a_{j}\left(z_{t-1}-\bar{z}\right)^{\psi_{j}}\left(k_{j, t-1}\right)^{\alpha_{j}}\left(L_{j, t}\right)^{1-\alpha_{j}}
$$

Second, we suppose that there are two components of public capital, $z_{1}$ and $z_{2}$, which are combined to form the aggregate $z$; the aggregation is done via a CES function, so

$$
z=\left(\gamma^{1 / \epsilon} z_{1}^{1-1 / \epsilon}+(1-\gamma)^{1 / \epsilon} z_{2}^{1-1 / \epsilon}\right)^{1 /(1-1 / \epsilon)}
$$

where $\epsilon$ is the elasticity of substitution between the two components. The composite $z$ now enters the production function 2.2 in place of a unitary $z$ and all other features of the previous analysis go through, contingent on the reinterpretation. If $\epsilon$ tends to infinity, the two components are perfect substitutes, and the composition of public investment is irrelevant; if $\epsilon=1$, the aggregator is itself Cobb-Douglas and the two components enter equation 2.2 with exponents $\psi \gamma$ and $\psi(1-\gamma)$ respectively; if $\epsilon=0$, they are perfect complements, and the level of effective public capital is entirely determined by the one that is in shorter supply, relative to the efficient ratio of $z_{1} / z_{2}=\gamma /(1-\gamma)$. Equation 2.3 can then be used in conjunction with equation (2.2) to explore how a given percentage loss in the public capital stock translates into some percentage loss in total output, with the scale of the impact depending on the efficient mix of the components (determined by $\gamma$ ), on the elasticity of substitution, and on how the loss is distributed between them, as well as on the scale of any threshold effect.

Appendix Table I illustrates these interactions given the baseline parameterization of the simulation model. When the elasticity of substitution between the components is arbitrarily high and there is no threshold, $(\bar{z}=0)$, neither the initial composition of capital nor the incidence of the loss affects the elasticity of output with respect to the capital stock, which is 0.27 . When there is a threshold, the elasticity of output increases, from 0.27 to 0.37 as long as the elasticity of substitution remains arbitrarily high. If, however, the elasticity of substitution is low, an unbalanced shock increases the elasticity of output, very dramatically so when the shock affects the relatively scarce component of the composite capital stock. For the cases illustrated in the table, the output elasticity could rise as high as 0.95 . In other words, in this relatively extreme case a 10 percent loss of installed capital concentrated on the scarce component of the capital aggregate would lead to a decline in the effective aggregate capital of 20.2 percent and a corresponding fall in steady state output of around 9.5 percent. 
The costs of public investment are not restricted to the upfront capital cost and associated financing; they also include ongoing recurrent costs for operations and maintenance, and since, even when adequately maintained, capital still depreciates, there will also be the cost of future replacement. The scale of recurrent costs per dollar of investment varies very significantly with the type of investment, tending to be much higher for social than for economic infrastructure (Heller, 1991). In addition, for reasons ranging from the technical to the political, government is typically unable or unwilling fully to recover these recurrent costs through user charges. In consequence, public investment creates fiscal burdens for which finance must be found. As will be discussed below, when disaster risk insurance is taken out, it covers only the capital cost of new investment.

Government is not modeled as an optimizer; it makes exogenous decisions, or follows rules of thumb. Its capital program may be inefficient, both in the quality of public investment and in implementing the additional operations and maintenance expenditures that the program requires. These inefficiencies mean respectively that an additional dollar of public investment may not lead to an additional dollar of public capital being installed; that what capital is installed may not deliver its full level of services; and that installed capital depreciates faster than it should. Unless great care is taken, these inefficiencies may all worsen during a phase of accelerated investment, whether this is occasioned by an ambitious investment program or the need to replace destroyed assets. There may also be adjustment costs during this phase, associated with capacity limitations in the private and public sectors, which raise the unit cost of investment.

As noted in the introduction, the damage inflicted by public capital destruction may include reduced incentives to replace destroyed private capital. The model is designed to track four types of loss. The first two are the direct damage to public and private capital assets. The third type covers temporary output losses additional to those reflecting the asset losses themselves. These might, for example, reflect damage to a third asset class, land, which is not included in the model specification. 3 The fourth type are the output losses, often termed "indirect" losses, which arise because reconstruction is slow. This paper focuses primarily on how this fourth type of loss can be mitigated by various financing mechanisms. 4 It is well known that a substantial part of post-disaster public financing comes from budget reallocation. As currently constituted, the model is suited to study only one type of reallocation, albeit a very important and possibly very costly one. This is the diversion of funds and personnel from operations and maintenance to reconstruction and rehabilitation. The diversion may be driven by budgetary constraints - the difficulty of raising additional revenue or undertaking additional borrowing - or by real

\footnotetext{
${ }^{3}$ Or indeed damage to a fourth asset class, temporary disruption of social capital.

${ }^{4}$ Of course, appropriate regulations and good design may also reduce the first three types of loss, but these are beyond the scope of the present analysis.
} 
resource constraints - the machinery and skilled labor that can reconstruct damaged bridges, for example, has to be drawn from the same pool as supplies bridge maintenance services.

Finally, we note some limitations. First, the model is a calibrated policy simulation framework designed to explore the properties of alternative scenarios and so cannot be used for forecasting. Second, as noted, it is not a monetary model, so it does not examine inflation or nominal exchange rate dynamics. Third, it is a value-added model, meaning that it cannot examine intermediate input linkages, and it is an aggregated macroeconomic model, so it cannot be used to examine sectoral composition (aside from that between tradable and non-tradables). Fourth, apart from aggregate public investment and the related operations and maintenance expenditures, other public expenditure is not modeled other than as a transfer to private consumers.

\section{Calibration, Disaster Risk, and Design of the Simulations}

To explore the role of disaster risk insurance, we run a small set of runs describing the macroeconomic consequences of a stylized natural disaster of varying intensity/likelihood that results in the catastrophic loss of public capital, using data for Jamaica to illustrate the procedure. As noted above, it would be a simple step to allow the disaster to wreak broader damage, on output and on private capital stocks, but here we limit our attention to the case where private capital escapes damage and where, if the government chooses to take out disaster risk insurance, it does so to cover only the risk to public capital. The model is currently calibrated to Financial Year 2013/14 based on national accounts data from the Statistical Institute of Jamaica and the IMF's 2014 Article IV Consultation 5 The main characteristics of the calibration are reported in Appendix Table II.

\subsection{Hazard risks and shock calibration}

The risk profile is developed from the data and analysis contained in "Catastrophe Risk Profile: Jamaica" produced by Evaluacion de Riesgos Naturales - America Latina, ERN (2009). This report combines estimates of exposure values for private and public capital stocks with hazard models for hurricane and earthquake damage to produce estimates of the probable maximum loss under alternative return periods. We modify these estimates in order to calibrate appropriatelyscaled shocks for the model economy. First, we extrapolate the ERN probable maximum loss (PML) functions to allow us to examine shocks that have a higher probability/ lower return period than considered in the ERN analysis. Second, focusing just on tropical cyclone risks, we recompute the losses and corresponding insurance premia for the case examined in the model, namely that cyclone damage affects only public capital (which accounts for approximately 25

\footnotetext{
${ }^{5}$ IMF (2014)
} 
percent of the total capital stock of the economy) and that government can insure just the public capital. Finally, we re-scale the relevant estimated values to 2013/14 US dollars to be consistent with the national accounts data to which the model is calibrated 6

In principle, we can run the model for any value drawn from the PML curve, under any chosen insurance contract, and under a wide range of model settings determining, amongst other things, the specific incidence of the disaster and the public policy response to it. This capacity gives us the opportunity to design a full-blown Monte Carlo analysis across the entire hazard distribution. Given the variations in disaster incidence, financing and economic structure we are interested in exploring, a full analysis of this type would entail an enormous amount of computing and an unwieldy volume of output. In this paper we therefore restrict ourselves to a more modest, deterministic, analysis in which we run the model for just five specific points on the PML curve: (i) no cyclone; (ii) a one-in-10 year intensity cyclone; (iii) a one-in-25 year cyclone; (iv) a one-in-100 year cyclone; and finally, (v) a one-in-500 year intensity cyclone. For each simulated disaster we explore the model economy's responses under the following variations:

- Disaster incidence. We consider two characterizations of the public capital stock and how the cyclone affects it. First we construct a balanced shock scenario where the aggregate public capital stock is a composite of two equally-sized components $\left[z_{1}\right.$ and $\left.z_{2}\right]$, which are highly substitutable (the elasticity of substitution, $\epsilon$ in 2.3 is arbitrarily large), and where the cyclone damages both components equally. $\left.\right|^{7}$ By contrast, a concentrated shock is one where the public capital stocks are different in size and are imperfect substitutes for each other, i.e. the elasticity of substitution between $z_{1}$ and $z_{2}$ is low $(\epsilon=0.25$, say, in 2.3. Then it will matter whether the relatively scarce or abundant component is more severely damaged. In both cases, a given overall loss of public capital will have a more adverse effect than in the balanced case, but this effect will be more severe if the scarcer type is disproportionately damaged. The latter type of concentrated shock is considered in the simulations reported below. Moreover, as shown in 2.2 , we assume in these cases a threshold effect for the public capital aggregate before it becomes productive; this is set to $25 \%$ of the baseline aggregate stock. This combination of settings in the concentrated shock case leverages the impact of any given destruction of public capital on the rest of the economy 8 The reason for wishing to explore this type of combination is that, given the Cobb Douglas structure utilized here, the balanced case almost certainly underestimates the output losses caused by damage to public capital. For example, if the elasticity of output with respect to public capital is 0.2 , as a number of empirical estimates suggest, a ten percent loss of public capital would only lower output by a little over 2 percent in the

\footnotetext{
${ }^{6}$ We are grateful to Richard Poulter for guidance on computing simulated losses and corresponding insurance premia for the different disaster risks.

${ }^{7}$ To a close approximation, this is equivalent to having a single public capital good.

${ }^{8}$ The final modification we consider here is to assume that when the shock is 'concentrated' in this fashion, the private sector also faces higher adjustment costs when rebuilding its capital.
} 
balanced case. The concentrated shock goes some way to rectifying this underestimation, since the reduction in effective public capital is greater than the reduction in installed capital. Of course, the insurer is concerned with the reduction in installed capital, and it is this that determines the premium that has to be paid. The benefit from the insurance (or indeed any other means of achieving the rebuild) is however determined by the (possibly greater) loss of effective capital.

- Insurance coverage. The government can choose the level of insurance coverage to purchase from an offshore provider. We consider two alternatives, a no-insurance case and an insurance contract that covers the full direct incremental cost of public investment at and in excess of the attachment level (voluntary excess) following any disaster. The contract is for a 1:10 attachment point.9 Payment is by means of grants to government which are increased dollar-for-dollar by the increase in public investment, at the initial value of the real exchange rate. The annual insurance premium is met from higher (distortionary) baseline domestic taxation. The tax distortion means that in the no-shock environment the economy operates with lower steady state private capital, output and consumption. As defined here, this is a very simple indemnity insurance contract. There is no basis risk, all public assets are insurable and the contract pays out immediately rebuilding expenditures are incurred. It would be straightfoward to extend the model to relax any and all of these assumptions to allow for the sort of basis risk that characterizes parametric insurance, for payouts not to be synchronized with expenditures, and for insurance coverage to be incomplete.

- Accelerated re-build We assume there are absorptive capacity constraints that limit the physical pace at which government can re-build the public capital stock following a natural disaster (independent of its ability to finance higher public investment). These constraints are assumed to limit the feasible increase in gross public investment to $2.0 \%$ of GDP per annum. (Baseline aggregate public investment is just over 5\% of GDP so this represents a 40 percent increase in the investment rate, post-disaster.) Insurance in this model not only provides resources but allows for a faster pace of public reconstruction, so that this physical limitation becomes the binding constraint. We assume that difficulties in raising tax rates or reallocating recurrent expenditure in the short to medium run mean that this physical limit is out of reach when the rebuild is financed in either of these ways, so that the binding constraint comes from financing, and this limits the rebuilding rate to roughly $1.0 \%$ of GDP. In other words, a major advantage in being insured is that the rebuild can be accelerated.

\footnotetext{
${ }^{9}$ We have explored alternative specifications of the insurance contract, such as a 1:25 attachment point, but the main findings of the paper are not sensitive to these choices.
} 


\subsection{Characterization of disaster risk}

Central to the analysis of whether, and in what circumstances, the sovereign should insure against natural disasters is some characterization of the probability distribution of the scale of the disaster. In this exercise, we have relied on the (modified) PML curve discussed above which gives estimates of the scale of the disaster at four hypothetical points corresponding to 1-in-10, 1-in-25, 1-in-100, and 1-in-500 return periods. For the present application, this presents three challenges. The first is to construct a tractable continuous distribution to provide a reasonable approximate fit to these numbers. The second and third arise from the fact that the macroeconomic model we use to analyze responses to shocks is complicated. Setting up and running a very large number of Monte Carlo simulations, which would be able to span this distribution adequately, is prohibitive. This means that a small number of specific cases need to be chosen for analysis, and the results aggregated in some appropriate probabilistic fashion. It seems natural to focus on the scale of disasters picked up by the four original "data points". However, it will be necessary to augment the associated probabilities of these events so as to capture the overall risk in an appropriate way. This is the second challenge. The third challenge is that while the underlying risk for year 1, say, has been resolved at the end of that year, the same distribution of risk is faced in year 2, and subsequent years, given the reasonable assumption that these sequential risks are independent. Hence, if the country is unlucky enough to be hit by a 1-in-500 event in year 1, it still faces a 1-in-500 risk of being hit by such an event in year 2, and so on. These sequential possibilities again multiply the possible cases beyond what can readily be implemented. There is no optimal way of handling any of these challenges, and all three have to be handled in a relatively arbitrary way. Our choices are spelled out below; it is obvious that other approaches would be possible, but some experimentation suggests that the outcomes may not be very sensitive to these choices.

\subsubsection{Choosing a distribution}

Two obvious candidates are the negative exponential and some version of a power law (Pareto distribution). For the data provided, the negative exponential appears to offer a much better fit, and that is what is used here. ${ }^{10}$ The standard form of negative exponential has

$$
P(D)=\lambda e^{-\lambda D}
$$

where $P(D)$ is the probability of an event of scale $D$. This integrates to 1 , and has mean value $\bar{D}=1 / \lambda$. In the present case, $D$ represents the value of the damage. However, $P(D)$

\footnotetext{
${ }^{10}$ This is a mild surprise, since power law distributions, with relatively thick tails, often seem to describe data better. It is also helpful, since a Pareto distribution has to have a positive lower bound, and there is no obvious reason for determining where this bound should be, but it is critical in determining the properties of the distribution, notably the mean expected damage.
} 
is the probability of damage $D$ conditional on there being any damage at all. There is also, say, a probability $\theta$ that no disaster occurs, in which case there is no damage at all. Hence the probability that there will be positive damage of $D$ is now

$$
P(D)=(1-\theta) \lambda e^{-\lambda D}
$$

Overall mean damage is now

$$
\theta * 0+(1-\theta) \int_{0}^{\infty} D \lambda e^{-\lambda D} d D=(1-\theta) / \lambda
$$

The numbers that follow are all in percent of GDP. The data from the modified PML curve suggest that the reduction in the installed capital stock would be $0.39 \%, 1.83 \%, 4.11 \%$, and $8.22 \%$ at the 1 -in-10, 1 -in-25, 1 -in-100, and 1-in-500 probabilities respectively. It is with these numbers that we work below. Rather than trying to get a "best fit" to them, we simply fit the negative exponential to the end points $(0.39 \%$ and $8.22 \%)$, which requires that $\lambda=0.4999$, as the solution to $0.1 / 0.002=e^{\lambda(8.22-0.39)}$. Substituting this value into equation 3.1 for either end point then yields $\theta=0.7567$. This crude procedure yields somewhat higher values of $2.22 \%$ and $5.00 \%$ for the intermediate cases, as opposed to the benchmark values of $1.83 \%$ and $4.11 \% .11$ So, on this calibration, some sort of event (disaster) will occur $24.33 \%$ of the time, and the mean value of damage will equal $(1-\theta) / \lambda=0.4866$ as a percent of GDP.

\subsubsection{Augmenting the probabilities}

It would, in principle, be possible to carry out a Monte Carlo simulation by taking some large number, $N$, of draws from the distribution described by equation 3.1. For example, if $N=$ 10,000 , the aggregate probability across these draws that some sort of event would be recorded would be very close to 0.2433 (close to 2,433 of the 10,000 draws would record positive damage) and the mean damage, averaged over these draws, would be very close to the value 0.4866 . By choosing $N$ sufficiently large, these discrepancies could be made arbitrarily small.

As noted earlier, it is impractical to run the model for a large number of different events. Instead we do so only for the four "observed" data points, plus the case where there is no event. However, summing the four probabilities yields a total probability of some event of only $0.152(0.1+0.04+0.01+0.002))$, and the average damage is only $0.1697(0.1 * 0.39+0.04 *$ $1.83+0.01 * 4.11+0.002 * 8.22)$. Hence, simply summing over the four types only produces $62.5 \%(0.152 / 0.2433)$ of the aggregate probability and only $34.9 \%(0.1697 / 0.4866)$ of the mean damage. Simple summation under-represents the true probability, but does so more severely in respect of the low probability, high damage end of the spectrum. The simplest correction is

\footnotetext{
${ }^{11}$ In a practical application of this method, it would be straightforward to utilize a more accurate fitting procedure, but the purpose here is purely illustrative.
} 
to augment the probabilities, with the rate of augmentation increasing as the probability falls. There would be many ways of doing this. The simple device, adopted here, is to make the rate of augmentation a polynomial. Then the probabilities are transformed as $0.1 \rightarrow 0.1 h$, $0.04 \rightarrow 0.04 h n, 0.01 \rightarrow 0.01 h n^{2}$, and $0.002 \rightarrow 0.002 h n^{3}$.

We require that:

$$
h\left(0.1+0.04 n+0.01 n^{2}+0.002 n^{3}\right)=0.2433
$$

and

$$
h\left(0.1 * 0.39+0.04 n * 1.83+0.01 n^{2} * 4.11+0.002 n^{3} * 8.22\right)=0.4866
$$

Solving these two equations yields values of $n=1.9594$ and $h=1.0494$, so that the augmentation in probabilities is $0.1 \rightarrow 0.1049,0.04 \rightarrow 0.0822,0.01 \rightarrow 0.0403$, and $0.002 \rightarrow$ 0.0158. The enhancement ratio, which has to sum to $0.2433 / 0.152=1.60$ is distributed as 1.05 , $2.06,4.03$, and 7.90. By design, these augmented probabilities not only sum to the same value that a full Monte Carlo simulation would yield, but also generate the same average loss.They are used in the simulations described in Section 5.

\subsubsection{Repeated exposure}

To keep the simulations tractable, we assume that the economy is exposed to the chosen risk distribution in the first year, but not in subsequent years. Either it escapes any initial disaster, and continues to follow the calibrated balanced growth path; or it suffers an initial shock of some magnitude, and follows some strategy of response to this, with the economy following a trajectory determined by these two factors. In either case, there are no subsequent shocks to handle. This contrasts with the perfectly appropriate approach in the insurance literature, where the country is modeled as drawing repeated samples from the underlying distribution, or, equivalently, as being able to buy annual insurance reflecting the annual risk distribution, with that distribution being replicated year on year.

In our modeling framework, allowing a probabilistic sequence of shocks to materialize over some long horizon, would again multiply the number of simulations to impractical levels. Truncating the risk in the way adopted here has the obvious effect of reducing the overall exposure to risk that the country faces, but it also reduces the insurance premium that would have to be paid. One way of testing whether this joint reduction is likely to bias the analysis is to raise the scale of the initial damage in the one-off case to something like the expected value of the repeated draws from the annual distribution. We explore this option in the subsequent analysis; the results presented below suggest that conclusions are relatively insensitive to this issue. 


\section{Public Policy Responses and Counterfactuals}

In practice, the government will typically respond to the disaster by rebuilding the destroyed capital. In the simulations we report below it temporarily raises its gross investment rate and seeks to restore the installed capital stock as quickly as possible given the imposed physical re-build limits discussed in the previous section. ${ }^{12}$ The timing convention in the model is that if a cyclone hits it does so only once and in period 1, reducing private output and consumption in period 2. The public investment response occurs in period 2 and adds to the installed capital stock with a one period lag. In practice, for a 1:25 cyclone this would see the public capital rebuilt at the end of the third year following the disaster in the case there is no insurance coverage, and a year earlier if insurance is in place. The accelerated rebuild benefits of insurance are greater in response to a 1:500 scale cyclone where insurance cuts the rebuild time from ten to five years. For simplicity, we assume no deterioration in the efficiency of public investment over the rebuild phase and similarly we discount any adjustment costs. Both factors are likely to be relevant in practice, when the pressure for a rapid rebuild drives up the cost of investment and drives down its efficiency.

The government will typically have recourse to a range of financing mechanisms: domestic tax financing; borrowing on non-concessional terms from private capital markets; re-allocation of public spending, including away from operations and maintenance of the existing capital stock; and disaster-risk insurance. In practice, these various financing alternatives are likely to be blended. Here we simplify the analysis by confronting government with a simple financing choice in which government either chooses not to take out disaster risk insurance, in which case all financing must be sourced from increased domestic taxation or budget reallocation, or it does take on insurance with full cover above the attachment point being purchased. 13 In the latter case, the insurance contract pays out only against the direct reconstruction costs; domestic taxation remains the residual financing instrument meeting any indirect costs arising from other general equilibrium changes in public expenditure occurring over the reconstruction and recovery phase.

\subsection{Alternative fiscal strategies}

One of the aims of this paper is to outline a procedure that enables us to compute the expected net cost of alternative public finance responses to natural disasters and to decompose these into the gross benefit from the rebuilding of the public capital stock and the gross cost of mobilizing

\footnotetext{
${ }^{12}$ We define the investment response in gross terms. This is for convenience only. What matters is the net investment, but the model's properties are invariant to whether the depreciation costs required to maintain the (rebuilt) additional capital are built in to the investment response or are met directly from the budget. We adopt the latter approach.

${ }^{13}$ In our interim report (Bevan and Adam, 2014) we explored a fuller range of financing.
} 
the required fiscal resources. As noted earlier, costs and benefits are measured in terms of real household consumption and the results are reported in Tables 1 to 3 .

We examine four alternative fiscal strategies as follows:

- Do nothing. In this run tax rates, transfers and the value of gross public investment are all held fixed at their baseline levels and O\&M expenditures remain at their efficient levels throughout 14 Prior to the natural disaster, gross investment is just sufficient to stabilize the public capital stock at its baseline steady state level so that net public investment is zero (relative to the underlying trend growth rate of the economy) 15 When the cyclone destroys part of the public capital stock, depreciation and efficient O\&M requirements fall. The original (baseline) gross public investment plus the O\&M 'savings' now finance positive net investment which generates an endogenous re-build of the public capital stock along an asymptotically convergent path. This passive response means that it takes a very long time for the rebuild to be substantial.

- Tax-financed rebuild. Here transfers are again held fixed and O\&M expenditures are maintained at their fully-efficient levels (relative to the evolving capital stock). Public investment is increased to rebuild the public capital stock subject to the restriction that gross public investment can be no more than $1 \%$ of initial GDP per annum higher than in the baseline. This constraint defines a rebuild profile for each draw from the distribution of cyclone intensities ${ }^{16}$ The additional cost of the enhanced public investment program, including associated O\&M expenditures, is financed solely through increased domestic taxation 17

- OEM expenditure reallocation. Tax rates and transfers are again held at their baseline levels. As in the previous run, the $1 \%$ of GDP ceiling on additional post-disaster investment continues to bind, but here the cost of the additional investment is met by re-allocating equal amounts of recurrent spending away from operations and maintenance expenditures. The reduction in O\&M expenditures relative to their efficient levels accelerates the depreciation of the public capital stock (due to deficient ' $M$ ') and lowers the flow of productive public capital services generated by the installed public capital (due to deficient 'O'). Crucially, deficient O\&M affects both the marginal and infra-marginal capital stocks.

- Insurance-financed rapid rebuild. In this run the government has taken out disaster-risk insurance which meets the full capital cost (but not the associated O\&M costs) of restoring

\footnotetext{
${ }^{14}$ Efficient O\&M requirements are defined relative to the stock of installed public capital. In the calibration used here fully efficient O\&M expenditures account for $2.5 \%$ of the capital stock each which corresponds to approximately $4.2 \%$ of GDP in the no-shock baseline.

${ }^{15}$ In the current calibration trend growth is set to $g=1.5 \%$ p.a., corresponding to recent per capita GDP growth in Jamaica.

${ }^{16}$ Each period additional gross public investment is set equal to the minimum of the feasible investment rate and the amount that returns the installed capital to its pre-disaster level (relative to trend).

${ }^{17}$ Consumption and factor taxes are increased in proportion to their baseline shares of tax revenue.
} 
the public capital stock to its pre-disaster level, paying out as and when additional investment expenditures are incurred. The contract is defined for a 1-in-10 attachment point with no maximum, paying out in the wake of all disasters of 1-in-10 year intensity or worse. Additionally, with insurance in place, government is able to rebuild the public capital more rapidly than before: specifically, public investment can increase by up to $2 \%$ of initial GDP per annum above baseline investment.

For each of these cases, the model is run to generate private consumption paths under each of five draws from the distribution of cyclone intensities (no shock; 1-in-10; 1-in-25; 1-in-100; and 1-in-500 year shocks). The present value of the consumption path for each draw from the shock distribution is then weighted by the probability weight for each shock, as described in Section 3 , to give the expected value of consumption for each strategy ${ }^{18}$ Consumption is discounted at the model-calibrated subjective discount rate for the representative household (in the current calibration this discount rate is $5.91 \%$ ). Expected consumption paths are compared to a baseline scenario - discussed below - by expressing the present value of the consumption gain or loss as a stationary annuity value, also calculated at the representative agent's discount rate. Finally, by comparing these values to the expected value of the initial loss of public capital due to cyclone damage, we report the internal rate of return (IRR) of each strategy. This last step is not straightforward, and is discussed in the subsection 4.3.

\subsection{The insurance premium}

It remains to calculate the insurance premium that is likely to be required by the insurer. As we understand it, this typically takes the form:

$$
\text { Prem }=E[\text { Loss }]+0.125 * S D[\text { Loss }]
$$

where Prem is the required premium, $E[$ Loss $]$ is the expected value of the loss that will be borne by the insurer, and $S D[L o s s]$ is the standard deviation of the losses borne by the insurer. The extent to which insurance is actuarially unfair is the captured by the insurance multiple, Mult, where:

$$
\text { Mult }=\text { Prem } / E[\text { Loss }]
$$

From the distribution fitted to data for cyclone damage in Jamaica, for a 1-in-10 attachment point, and no exhaustion point, the estimated value of the multiple is 1.62 . Given that we are forced to adopt a rather recondite sampling process to model the losses, the standard deviation in the model would typically come in at a lower value than this. Since this is an aretefact of the modeling procedure (which focuses on replicating the expected loss, not its standard deviation), we have chosen to maintain a premium at 1.62 times the expected loss in all cases.

\footnotetext{
${ }^{18}$ For each run, the model computes a 1000 period consumption path.
} 


\subsection{The counterfactual, gross costs and gross benefits}

There is no perfect counterfactual for this exercise. One option, of course, is a simple 'nodisaster' scenario but this is unappealing since it implies a wholly different and unrealistic meta-environment for the analysis. An alternative, which does admit the risk environment, is where the authorities treat the natural disaster in a fatalistic manner and simply seek to stabilize the economy at whatever level of public capital that remains undamaged. This too is an unattractive counterfactual: while we have not assumed the authorities to have optimized the level of public capital, we do assume that some choice underpins the level of public investment and capital stock in the baseline steady state so that a strategy that simply accepts whatever the reduced capital stock turns out to be is implausible. A more plausible counterfactual, and the one used in the analysis here is the 'do nothing' strategy. Government holds its gross investment rate and its pre-disaster level so that capital returns slowly to its original level following a natural disaster by maintaining existing spending levels, not through any purposive change in fiscal direction by the authorities.

We use the model to decompose the net effect of each strategy into the gross cost associated with mobilizing fiscal resources for reconstruction and the gross benefit of the actual capital reconstruction itself. The net effect is generated directly from the various model runs. We then compute the gross benefit of reconstruction by imagining a 'reverse cyclone' which instead of destroying capital has the property that it reconstructs capital at no cost but according to one or other of the rebuild scenarios described above. The annuity value of the consumption gain from this (relative to 'do nothing') can then be compared to the dollar cost of the original damage to compute an internal rate of return. In effect, this procedure calculates the IRR associated with the rebuild if the cost of a dollar of funds was indeed a dollar. With this in hand we then derive the gross cost of mobilizing fiscal resources by subtracting the net benefit (which may of course be negative) from this gross benefit. The reason for adopting this residual approach rather than computing the gross cost directly is that there are complex general equilibrium effects at work, which are mostly attributable to the financing mechanisms. The residual approach is appropriate because it attributes these effects to the gross cost calculation. In general, it means that the financing cost is greater than its face value, and possibly substantially greater.

\section{Simulation Results}

In this section, we report a small number of the simulation runs we have conducted. We begin by illustrating, in Figures 1 and 2, the sort of evolution following a specific (large) shock that the model generates, given the different policy responses outlined above. We then tabulate, in Tables 1, 2 and 3, summary results for three different situations, given these responses, using the augmented probabilities constructed in Section 3. Table 1 concerns our baseline, the concentrated case using the scale of shocks discussed in that section; Table 2 repeats the exercise 
for the balanced case; and Table 3 revisits the concentrated case, but now considers much larger levels of damage at the same probabilities. At each probability, the damage is 3.5 times that examined in Table 1.

\subsection{Evolution of the economy - an illustration}

Before examining the detailed results, we briefly describe the evolution of the model economy in response to a specific disaster.

Figures 1 and 2 provide some intuition as to the properties of the simulation runs. Both illustrate the extreme case of a 1-in-500 cyclone, so movements are dramatically more pronounced than for less severe shocks. The case considered is for the concentrated version of the shock, with the scarcer component of public capital more heavily damaged. Specifically, it is assumed that the scarce capital stock initially comprises $40 \%$ of the total, but bears the entire brunt of the losses induced by the disaster. The same characterization is used in the Tables 1 and 3 below.

Figure 1 displays the paths of investment, capital stocks, GDP, and aggregate private consumption as well as the returns on capital and required tax revenue when the rebuild is entirely tax financed. In this case, the reconstruction process takes a full decade, with an increase in tax required of the order 1.5\%-2\% of GDP over that period. Even though private capital escapes the disaster, the investment rate and hence the private capital stock still fall, reflecting the fall in the private return to capital induced by complementarity with the reduced public capital. Both GDP and consumption fall sharply, and are slow to recover.

For the same shock, Figure 2 compares what happens under the four scenarios discussed above, "do nothing", expenditure reallocation, tax financing, and insurance. It restricts itself to graphing the paths of effective public capital and private consumption under these scenarios. As noted, insurance is assumed to permit a more rapid rebuild than tax finance, and, a fortiori, than "do nothing". It also yields a higher consumption path than the tax financed path; however, this is a reflection of the fact that the value of insurance is highest when the worst case materializes. It would be reversed if the paths for higher probability, lower damage events were plotted. The net effects, across the range of events, are examined in Tables 1, 2 and 3 below.

The more dramatic feature of Figure 2 is the catastrophic consequences of expenditure reallocation when this involves sharp reductions in O\&M spending. Both effective public capital and consumption fall very sharply, remain very depressed for a decade, and have still not fully recovered after 30 years. Of course, it might be possible to find other components of government recurrent expenditure which could be compressed at much lower cost, but experience suggests that this is not easy, and the present results suggest a high degree of caution in relying on reallocation as a financing mechanism. Once again, more light is thrown on these issues in the tables. 


\subsection{More detailed results}

In Tables 1 to 3 three different illustrations of these calculations are given.

The layout of each table is the same. The first row gives the augmented probabilities of each level of cyclone intensity, with these probabilities being common across the three tables. For each intensity, the table then gives the annuity impact on consumption for each type of response, distinguishing between the gross and net effects according to the procedures outlined in Section 4.3. These event specific outcomes are then aggregated, using the augmented probabilities, into expected annuity values, for the net and gross cases. Finally, at the right hand side of the tables, these are converted into IRRs, using the original capital loss as the denominator. In effect, this procedure says that, if a dollar of funds could be raised with no other implications, what would be the IRR from deploying them in the specified way? And symmetrically, if a dollar of funds had to be put into the government's hands using a specified financing technique, what would the opportunity cost of those funds be, expressed as an annuitized cost of capital?

The first case, which may be taken as the base case, is illustrated in Table 1; it calculates the costs and benefits when the shock is scaled by the underlying distribution, but as a one-off, and the public capital losses are concentrated. Table 2 repeats the exercise for the balanced shock case, with the same initial destruction, while Table 3 repeats the exercise of Table 1 , but this time scales up the shock so that the initial one off hit has a similar expected destructive consequence as implied by the full multi-year risk profile. For each of the four fiscal responses (do nothing (Case I), raise tax (Case II), reallocate O\&M (Case III), take out insurance (Case IV)), these tables show the annuity consumption effects for each of the five events considered. They also show the net expected value across these events. Following the earlier discussion, they partition this net effect into its gross benefit and, residually, its gross cost components, relative to the "do nothing" counterfactual. In each case, the insurance premium is taken to be a multiple of the insurer's expected cost as given by the actuarial formula relating this premium to the expected loss and its standard deviation. For the data given in the Jamaica case, for a ten year return contract, this multiple would be 1.62. The associated IRRs are also given. These results are illustrative and reflect the specific calibration, of both the risk environment and the general equilibrium behavior, we have employed here. The method itself, however, is amenable to changes in either or both aspects of the calibration.

\subsubsection{Table 1}

Table 1 summarizes the results for the base case. The expected value of the capital loss is $0.487 \%$ of GDP, equivalent to an annuity value at a $5.91 \%$ discount rate of $0.029 \%$. The key figures are in the final columns where we report the net and gross annuity value in percentage points of current GDP and corresponding IRRs associated with alternative sources of financing and the gain in consumption from the rebuild. The first row in the table gives a sense of the overall 
expected burden associated with the cyclone risk profile faced by Jamaica, as characterized by our model where, as we noted in our earlier paper, the overall effects are modest in part because cyclone damage is assumed to destroy public infrastructure capital only. Relative to the 'do nothing' counterfactual, the complete absence of risk events affecting the public capital stock would lead to a permanent $0.079 \%$ increase in consumption. If it were possible to pay sums that would prevent the losses from happening, dollar for dollar, these payments would have an IRR of $16.3 \%$

The results for Case II gives a clearer insight into the analysis. What these say is that tax financing the reconstruction of public capital, subject to the ceiling on the maximum feasible volume of additional public investment, generates an annuity consumption gain of $0.031 \%$ of baseline GDP per annum relative to the counterfactual of doing nothing. This net gain is composed of a gross consumption gain to the (more-rapid-than-counterfactual) capital reconstruction, equivalent to a permanent $0.067 \%$ of baseline GDP, and a permanent loss of consumption arising from higher taxation equivalent to $0.037 \%$ of GDP. Based on the disaster risk profile, the expected value of the loss of public capital arising from cyclones of differing intensities is computed to be $0.487 \%$ of baseline GDP. Using this, the IRR for Case II is $6.3 \%$. The corresponding gross benefit and cost IRRs are $13.9 \%$ and $-7.6 \%$ respectively.

Case III examines the outcome where the capital rebuild is financed by reallocating recurrent expenditures away from O\&M. The gross benefit from the rebuild is exactly as in Case II but in this instance the gross cost is almost six times higher (the annuity value of lost consumption is more than $0.21 \%$ of initial GDP). In net terms this strategy is very unattractive generating an IRR of $-30.2 \%$. The reason is simple; economizing on O\&M accelerates the depreciation and reduces the effectiveness of public capital across the board, reducing not just the contribution of the rebuilt capital to private output but also the contribution of public capital that survives the cyclone unscathed.

Finally, Case IV leads to a somewhat ambiguous result. The expected gross benefit from the accelerated rebuild is higher than before - the IRR of rebuilding is now $14.8 \%$ and is particularly favorable in the face of large disasters - but so is the expected gross cost. In this case the cost burden arises primarily from the cost of carrying the insurance premium in the absence of large disasters. The opportunity cost of insurance is $13.0 \%$, leaving the net gain from this policy at $1.8 \%$ - very marginal.

\subsubsection{Table 2}

This replicates Table 1 in respect of the size of the shock, but this is now distributed uniformly, or alternatively, across public capital stocks which are very good substitutes for each other. As expected, this reduces the pay-off to accelerated rebuild. Using the IRR metric, relative to Table 1, the net gains from the tax option fall from $6.3 \%$ to $4.5 \%$, those for the insurance option are changed from $1.8 \%$ to $-1.0 \%$, while those for the reallocation case moderate from $-30.2 \%$ to 
$-26.5 \%$. The reallocation option remains deeply unattractive, while the insurance option moves from being marginally favorable to marginally unfavorable. The insurance cost is the same in each case but since the asset being destroyed and rebuilt is initially more abundant and hence less valuable, the benefit of the accelerated rebuild falls by more than the gross cost of the insurance contract. This illustrates the sensitivity of the insurance calculation to the relative productivity of components of the public capital stock.

\subsubsection{Table 3}

This replicates the set-up as in Table 1, that is for the concentrated shock, but now raises the expected value of the scale of the losses by a factor of 3.5. This brings it reasonably close (at $0.101 \%$ of GDP) to the expected value in the original data, which is equal to an annual $0.149 \%$ of GDP. While these values for the losses are scaled up, so are the annuity losses and the premium. (Nothing in the scaling-up process has altered the distributional characteristics, other than the mean - in particular, the standard deviation as used in the insurance formula, is scaled with the mean i.e. the coefficient of variation is unaffected.) In consequence, the insurance premium rises proportionately with the expected value of the loss, the multiple remaining at 1.62. It would not be possible to impose much greater shocks than this in the present framework, since, at the 1-in-500 case, this comes close to eliminating the scarce component of public capital altogether. Despite this very large change in scale, the results are rather stable. Compared to those in Table 1, and again using the IRR metric, the net gains from the tax option rise from $6.3 \%$ to $6.7 \%$, those for the insurance option are changed from $1.8 \%$ to $2.0 \%$, while those for the reallocation case moderate from $-30.2 \%$ to $-25.5 \%$. The broad conclusion is that, at least over this very considerable range, the present results are very insensitive to scale.

\section{Summary and Conclusions}

\subsection{The current exercise}

Quite apart from the immediate and ongoing humanitarian issues they pose, natural disasters have widespread economic impacts, not least to capital assets. These impacts, in turn, pose a variety of challenges to public policy in general and to choices over the public finances in particular. This paper sets out to show how a model developed in another context may help to throw some light on these choices. The model is a real open economy general equilibrium model, but also has extensive public finance and public expenditure components which permit treatment of the complementarity between public and private capital and between components of public infrastructure capital; the distortionary nature of domestic taxation; the efficiency, or lack thereof, of public investment programs; and the central role of recurrent expenditures in maintaining and operating public capital. The framework also incorporates adjustment costs in 
(public and private) capital formation so that attempts to accelerate post-disaster reconstruction confront investors with rising marginal costs / falling marginal efficiency of investment.

The model is well-adapted to examining quite complicated events, including damage to public and private capital, as well as other mechanisms leading to temporary losses of current output. It is capable of comparing quite varied financing packages, including domestic taxation, domestic borrowing, external concessional and non-concessional borrowing, external grants, and public expenditure reallocation, with or without accompanying insurance contracts. However, while all these options are available and could be used to examine explicit proposals in a particular country context, the range of possibilities is too wide for it to be possible meaningfully to explore them at a general level.

In consequence, this paper has pursued a more limited set of choices. The model has been calibrated to recent national accounts data for Jamaica, and the paper draws on a recent risk profile for that country. Only part of that profile is utilized, pertaining to public capital damage only, with the associated problem of rebuilding this damaged capital, and how that is to be financed. The financing choice is restricted: the government may choose to rely entirely on temporary increases in taxation; it may choose to reallocate existing recurrent expenditure, specifically away from O\&M spending; or it may choose to take out insurance for $100 \%$ of the damage, above a certain "attachment point" - in effect, the government has to choose what level of excess to bear before the insurance kicks in. In the event of a disaster, insurance may permit a more rapid rebuild, given limits on how high domestic taxes can rise, and limits on how much reallocation is feasible. However, there are physical limits to the rate at which rebuilding can take place, however much finance is available. The benefit of faster rebuilding is to reduce so called "indirect losses", which are the losses of output which are caused by the reduced capital stock prior to the completion of rebuilding. The gain from this accelerated rebuild must be offset against the two facts that, first, the insurance premium still has to be paid, even in the (most likely) case that no disaster occurs during the insured period, and, second, that the insurance is available only on actuarially unfair terms.

\subsection{Inputs to other modeling approaches}

Models like this are complicated and quite difficult to manage. Experience suggests that it is difficult to devolve the necessary technical capability to central banks, ministries of finance and planning, or university departments of economics in low-income countries. Hence a second objective of the paper is to explore whether it can be used by a more central agency to provide inputs into some more tractable model designed to assess what options government should pursue. Some of these simpler models require reduced form summary statistics, such as estimates of the opportunity cost of various funding mechanisms, and internal rates of return to various rebuild scenarios. This paper suggests that this sort of model interaction is feasible, and may be a fruitful avenue to pursue. 
Subject to all the preceding caveats, the conclusions are as follows.

(1) It is indeed possible, as previously discussed, to use the model to generate estimates of the opportunity costs of funds and rates of return to more rapid rebuilds required by simpler models.

(2) Since the present model can only generate results for some package involving both a rebuild program and an associated financing device, it delivers a net result representing that particular combination.

(3) To disaggregate this net figure into its gross components, some strategy has to be adopted. The strategy adopted here seems the cleanest and most appropriate way of doing this, namely to assume that the benefits of faster rebuild can be estimated assuming funds are available at face value in ways that have no other repercussions, and to estimate the costs of a particular financing mechanism as a residual.

(4) The IRR of a faster rebuild appears, for the cases considered, to be in the range $11 \%-17 \%$. The opportunity cost of funds is highly variable; if a tax financing regime were feasible, this might be only around $6 \%-9 \%$, but if re-allocations from O\&M were used, this might be as high as $37 \%-44 \%$. The opportunity costs of insurance, on the other hand, might fall in the range 12\%-15\%, higher than the tax alternative, but much lower than the reallocation fro O\&M.

(5) In consequence, for the cases considered, a faster rebuild is not worth attempting if it has to be financed by reallocation from O\&M. It would always be worth undertaking if tax finance was feasible, and might, or might not, be worth undertaking via insurance, depending on details. Of course, as stressed previously, other forms of reallocation might be much less costly.

\subsection{The bottom line}

The main conclusions of the analysis are as follows. Even though the model allows for the distortionary effects of tax financing, in the absence of donor grants this remains the best method of financing the rebuild, and is always preferable to insurance in an either-or choice. However, this presupposes that increased taxation on the required scale is feasible. Meanwhile, any diversion of recurrent spending from $O \& M$ is likely to be very costly, and worse than a do-nothing approach. If increased taxation is infeasible, whether an insurance contract should be taken out is quite dependent on the details of the situation. It may be helpful, in the concentrated case, but not in the balanced one. Local knowledge should be decisive in these cases. More complex options, which combine tax and insurance, have not been considered in the analysis. One possibility is to use available tax capacity to self-insure against relatively high frequency events, and to supplement this with external insurance for low-frequency, high damage events. Exploring this type of option is left for subsequent work. 


\section{References}

- Adam, Christopher and David Bevan, (2014), "Public Investment, Public Finance and Growth: the Impact of Distortionary Taxation, Recurrent Costs and Incomplete Appropriability", IMF Working Paper WP14/73.

- Bevan, David and Christopher Adam, (2014), "Macroeconomic Modelling of Responses to Natural Disasters: an interim assessment with an application to Jamaica", mimeo, University of Oxford.

- Buffie, Edward, Andrew Berg, Catherine Pattillo, Rafael Portillo and Louis-Felippe Zanna, (2012), "Public Investment, Growth, and Debt Sustainability: Putting Together the Pieces.", IMF Working Paper WP12/144.

- Evaluación de Riesgos Naturales - América Latina, (2009), "Catastrophe Risk Profile: Jamaica" Inter-American Development Bank.

- Fay, M. and T. Yepes (2003) Investing in Infrastructure: What is Needed from 2000 to 2010? World Bank Working Paper WPS 3102.

- Heller, P. S. (1991) 'Operations and Maintenance', in IMF Public Expenditure Handbook Washington DC: IMF.

- IMF, (2014), Jamaica Article IV Report, Country Report 14/169.

- Rioja, F.K. (2003) 'Filling Potholes: Macroeconomic Effects of Maintenance versus New Investments in Public Infrastructure', Journal of Public Economics 87: 2281-2304.

- Statistical Institute of Jamaica, (2015), National Accounts, 2013-14. 


\section{Appendix I: The Model}

The model describes a two-sector small open economy producing a traded good $q_{x}$ and a nontraded good $q_{n}$ from private capital, labor, and government-supplied infrastructure. Households consume domestically-produced goods along with imported consumption goods $c_{m}$. Capital goods (machines) $m_{m}$, are also imported and combined with the non-traded good to produce private capital and infrastructure (public capital). All quantity variables except labor are detrended by $(1+g)^{t}$, where $g$ is the exogenous long-run growth rate of real GDP and $t$ is the time index. The model abstracts from money and all nominal rigidities, but includes taxation and a lump-sum transfer from government to private agents, as well as grants, remittances and a variety of forms of public and private debt.

\subsection{Firms}

\subsubsection{Technology}

The present model is an adaptation of a model designed to permit an integrated analysis of public investment, taxation, debt sustainability and growth. $\sqrt{19}$ We begin by sketching the technology assumptions in the original model and then introduce two adaptations. In each productive sector $j=n, x$, the representative firm uses a Cobb-Douglas technology to convert labor $L_{j, t}$, private capital $k_{j, t-1}$, and "effectively productive" infrastructure $z_{t-1}^{e}$, which is a non-excludable public good, into output:

$$
q_{j, t}=a_{j}\left(z_{t-1}^{e}\right)^{\psi_{j}}\left(k_{j, t-1}\right)^{\alpha_{j}}\left(L_{j, t}\right)^{1-\alpha_{j}}
$$

where the $a_{j}$ are sector-specific productivities. There are constant returns to private factors, with capital shares $\alpha_{j}$, but increasing returns in the presence of public infrastructure as measured by $\psi_{j}$.

Public and private capital is built by combining imported machines and a non-traded input (e.g., construction) in fixed proportions, determined by $a_{k}$ and $a_{z}$ respectively. The supply prices of private capital and infrastructure are thus:

$$
\begin{aligned}
& P_{k, t}=\left(1-a_{k}\right) P_{m, t}+a_{k} P_{n, t} \\
& P_{z, t}=\left(1-a_{z}\right) P_{m, t}+a_{z} P_{n, t}
\end{aligned}
$$

where $P_{n}$ is the price of the non-traded good and $P_{m}$ the price of imported machinery.

\footnotetext{
${ }^{19}$ The original model is Buffie et al 2012. A version with a much richer treatment of public finance is Adam and Bevan 2014. The present model is an adaptation of the latter.
} 
While this specification serves quite well in the context for which it was designed, it is not well suited to studying the impact of catastrophic damage to the public capital stock. Cobb-Douglas production functions are very convenient, but, in the normal set-up, have two major drawbacks. First, a given percentage reduction in the public capital stock causes a rather attenuated reduction in output; for example, with the sort of elasticity of output to public capital that is commonly assumed, such as 0.2 , a $20 \%$ reduction in public capital would only lower output by $4.4 \%$. Second, this attenuated percentage output reduction is uniform, regardless of how inadequate or indeed excessive was the level of the initial public capital stock. Switching to a somewhat more general formulation, such as a constant elasticity of substitution (CES) function with respect to the factors makes the solutions very complicated, with changes in public capital entering all the first order conditions in very complicated ways. The approach here is different, retaining the Cobb Douglas specification, but modifying it in two ways.

First, it is assumed that there is a threshold effect for public capital, embodied in $\bar{z}$, before it becomes productive. One could think of a network, such as a road system, where odd bits of road make very little contribution to output, but a connected system does.

$$
q_{j, t}=a_{j}\left(z_{t-1}^{e}-\bar{z}\right)^{\psi_{j}}\left(k_{j, t-1}\right)^{\alpha_{j}}\left(L_{j, t}\right)^{1-\alpha_{j}}
$$

We also suppose that there are two components of public capital, $z_{1}$ and $z_{2}$, which are combined to form the aggregate $z$; the aggregation is done via a CES function, so

$$
z=\left(\gamma^{1 / \epsilon} z_{1}^{1-1 / \epsilon}+(1-\gamma)^{1 / \epsilon} z_{2}^{1-1 / \epsilon}\right)^{1 /(1-1 / \epsilon)}
$$

where $\epsilon$ is the elasticity of substitution between the two components. The composite $z$ now enters the production function 7.1 or 7.4 in place of the previous unitary $z$ and all other features of the previous analysis go through, contingent on the reinterpretation. If $\epsilon$ tends to infinity, the two components are perfect substitutes, and the composition of public investment is irrelevant; if $\epsilon=1$, the aggregator is itself Cobb-Douglas and the two components enter equation 7.4 with exponents $\psi \gamma$ and $\psi(1-\gamma)$ respectively; if $\epsilon=0$, they are perfect complements, and the level of effective public capital is entirely determined by the one that is in shorter supply, relative to the efficient ratio of $z_{1} / z_{2}=\gamma /(1-\gamma)$. Equation 7.5 can then be used in conjunction with equation 7.4 to explore how a given percentage loss in the public capital stock translates into some percentage loss in total output, with the scale of the impact depending on the efficient mix of the components (determined by $\gamma$ ), on the elasticity of substitution, and on how the loss is distributed between them, as well as on the scale of any threshold effect.

\subsubsection{Factor demands}

Competitive profit-maximizing firms equate the (private) marginal value product of each input to its factor price, 


$$
\begin{gathered}
P_{j, t}\left(1-\alpha_{j}\right) \frac{q_{j, t}}{L_{j, t}}=\left(1+\theta_{w, t}\right) w_{t} \\
P_{j, t} \alpha_{j} \frac{q_{j, t}}{k_{j, t-1}}=\left(1+\theta_{j, t}\right) r_{j, t}
\end{gathered}
$$

for $j=x, n$ where $w$ is the net of tax wage, $r_{j}$ is the net rental earned by capital in sector $j$ and $\theta_{w}$ and $\theta_{j}$ are tax rates on labor and (sector-specific) capital income respectively. Labor is intersectorally mobile, so the same wage appears in $(7.6)$ for $j=x$ and $j=n$. Capital is sector-specific but at equilibrium the allocation of $k_{x}$ and $k_{n}$ ensures net-of-tax rentals are equalized. Critically, taxes on factors drive wedges between private and social values. In the presence of a tax on labor, the real wage is reduced below the marginal product of labor. For private capital, faced with a given steady state $r$, which is determined in the model by savers' preference parameters over the infinite horizon, the output to capital ratio must rise by $\left(1+\theta_{j}\right)$. This, in turn, means private capital stocks are lower than would have been the case in the absence of capital taxes, for example had all government revenue been raised from a lump sum tax. Notice, also, that the lower capital stock in equilibrium lowers the marginal product of labor (and the real wage).

\subsection{Households}

There are two types of private households, savers and non-savers, distinguished by the superscripts $i=s, h$ respectively. The ratio of non-saver to saver households is given by $a$. Households are infinitely-lived with utility, for both savers and non-savers, defined by the following function:

$$
U^{i}=\sum_{t=0}^{\infty} \beta^{t}\left[\frac{\left(c_{t}^{i}\right)^{1-1 / \tau^{i}}}{1-1 / \tau^{i}}-\kappa^{i} \frac{\left(L_{t}^{i}\right)^{1+1 / \iota^{i}}}{1+1 / \iota^{i}}\right]
$$

where $\beta$ is the discount factor; $\tau$ is the inter-temporal elasticity of substitution in consumption and $\iota$ the 'Frisch' elasticity of labor supply. Aggregate consumption, $c_{t}$, is defined as a constant elasticity of substitution (CES) aggregate defined over the domestic traded good $c_{x, t}^{i}$, the foreign traded good $c_{m, t}^{i}$, and the domestic non-traded good $c_{n, t}^{i}$ for $i=s, h$, thus:

$$
c_{t}^{i}=\left[\rho_{x}^{\frac{1}{\epsilon}}\left(c_{x, t}^{i}\right)^{\frac{\epsilon-1}{\epsilon}}+\rho_{m}^{\frac{1}{\epsilon}}\left(c_{m, t}^{i}\right)^{\frac{\epsilon-1}{\epsilon}}+\rho_{n}^{\frac{1}{\epsilon}}\left(c_{n, t}^{i}\right)^{\frac{\epsilon-1}{\epsilon}}\right]^{\frac{\epsilon}{\epsilon-1}}
$$

for $i=s, h$ where $\rho_{x}, \rho_{m}$, and $\rho_{n}$ are CES distribution parameters with $\rho_{x}+\rho_{m}+\rho_{n}=1$, and $\epsilon$ is the elasticity of substitution between the commodities. These parameters are common across the two households. The true consumer price index associated with the (common) consumption 
basket 7.9 is:

$$
P c_{t}=\left[\rho_{x} P_{c x, t}^{1-\epsilon}+\rho_{m} P_{c m, t}^{1-\epsilon}+\rho_{n} P_{c n, t}^{1-\epsilon}\right]^{\frac{1}{1-\epsilon}}
$$

with demand functions for each good:

$$
c_{l, t}^{i}=\rho_{l}\left(\frac{P_{c l, t}}{P c_{t}}\right)^{-\epsilon} c_{t}^{i}
$$

for $l=x, m, n$ and $i=s, h$. Consumer prices are defined as

$$
P_{c l, t}=\left(1+h_{l}\right) P_{l, t}
$$

where $h_{l}$ denotes the consumption tax rate on commodity $c_{l}$.

\subsubsection{Household budget constraints and first order conditions}

The representative saving household spends on final consumption, $c_{t}^{s}$, invests quantities $i_{x}$ and $i_{n}$ in private capital that depreciates at the rate $\delta$, pays user fees charged for infrastructure services according to $\mu z^{i}$, and buys domestic bonds $b_{t}^{s}$. Domestic bonds, which cannot be held by foreigners, pay a real interest rate $r$. This household maximizes its utility 7.8 for $i=s$ subject to the budget constraint:

$$
\begin{gathered}
\triangle b_{t}^{s}=\sum_{j}\left(1+\left(1-t_{j}\right) \theta_{j, t}\right) r_{j, t} k_{j, t-1}^{s}+\frac{1}{1+a}\left[\left(1+\left(1-t_{w}\right) \theta_{w, t}\right) w_{t}\left(L_{n, t}+L_{x, t}\right)+T_{t}+R_{t}\right. \\
\left.+\sum_{l}\left(1-t_{c l}\right) h_{l, t} P_{l, t} c_{l t}-\mu z_{t-1}^{i}\right]+r_{t-1} b_{t-1}^{s}-P_{k, t}\left(i_{x, t}^{s}+i_{n, t}^{s}\right)-P c_{t} c_{t}^{s}
\end{gathered}
$$

where $\triangle b_{t}^{s}=b_{t}^{s}-b_{t-1}^{s}$ and the equations of motion for capital in the tradable and non-tradable sectors respectively are

$$
(1+g) k_{j, t}^{s}=i_{j, t}^{s}+(1-\delta) k_{j, t-1}^{s}
$$

for $j=x, n$. The household receives a flow of remittances from overseas, $R_{t}$ and transfers from government, $T_{t}$. The household also pays taxes. The terms $t_{c x}, t_{c m}, t_{c n}, t_{w}, t_{x}, t_{n}$ represents the proportion of the tax revenue levied on consumption and on factors that finds its way to government (with $1-t_{s}$ the proportion retained by households for each tax, $s$ ). These tax wedges are discussed in more detail below, but essentially the terms in $t$ in 7.10 capture tax revenue that does not get remitted to government. Remittances, transfers and the 'retained' taxes paid on wages and user charges for infrastructure are proportional to the agent's share in aggregate employment.

The first order conditions describing the solution to the saving household's optimization problem are: 


$$
\begin{gathered}
\frac{c_{t+1}^{s}}{c_{t}^{s}}=\left(\beta \frac{1+r_{t}}{1+g} \frac{P c_{t}}{P c_{t+1}}\right)^{\tau^{s}} \\
L_{t}^{s}=\left[\left(c_{t}^{s}\right)^{-1 / \tau^{s}}\left(\frac{1}{\kappa^{s}}\right) \frac{w_{t}}{P c_{t}}\right]^{\iota^{s}} \\
\frac{r_{j, t+1}}{P_{k, t+1}}+1-\delta=\left(1+r_{t}\right) \frac{P_{k, t}}{P_{k, t+1}}
\end{gathered}
$$

Equation 7.12 is an Euler equation in which the slope of the consumption path depends on the bond interest rate adjusted for trend growth $(g)$ and on changes in the (tax inclusive) consumer price index. Equation 7.13 is the saving household's labor supply equation, and 7.14 the arbitrage conditions, requiring the rate of return on capital in each sector $j=x, n$ to equal the interest rate.

Non-savers maximize the same utility function as that of savers (7.8). The labor supply by this household is analogous to 7.13 and is given by

$$
L_{t}^{h}=\left[\left(c_{t}^{h}\right)^{-1 / \tau^{h}}\left(\frac{1}{\kappa^{h}}\right) \frac{w_{t}}{P c_{t}}\right]^{\iota^{h}}
$$

With no access to capital markets, however, non-saving households have no claims on either fixed capital or on bonds so that their income consists of wages, remittances, transfers and their share of the labor and consumption taxes not remitted to government less their share of user fees for the use of public capital. The consumption of non-saving households is therefore defined directly from their budget constraint :

$$
P c_{t} c_{t}^{h}=\frac{a}{1+a}\left[\left(1+\left(1-t_{w}\right) \theta_{w, t}\right) w_{t}\left(L_{n, t}+L_{x, t}\right)+T_{t}+R_{t}+\sum_{l}\left(1-t_{c l}\right) h_{l, t} P_{l, t} c_{l t}-\mu z_{t-1}^{i}\right]
$$

These hand-to-mouth consumers are a realistic feature of the data and their inclusion breaks Ricardian equivalence. Households are aggregated over $i=s, h$, so that $x_{t}=x_{t}^{s}+x_{t}^{h}$ for $x_{t}=c_{l, t}, L_{t}, b_{t}, i_{j, t}, k_{j, t}$, and the sub-indices $l=x, n, m$ and $j=x, n$. By definition, for non-saving households $b_{t}^{h}=i_{j, t}^{h}=k_{j, t}^{h}=0$ for $j=x, n$.

\subsection{The Government}

Government provides public infrastructure and makes transfers to both households. To finance these activities it raises taxes on domestic economic activity, borrows from domestic and external creditors and receives concessional aid and grants from development partners. Government may also levy user charges on households for the use of public capital. We describe these elements in turn: 


\subsubsection{Infrastructure, public investment and efficiency}

The model allows for inefficiencies in the construction and use of public capital. This requires us to distinguish between three different notions of public capital: notional capital $(z)$; installed capital $\left(z^{i}\right)$; and effective (or effectively productive) capital $\left(z^{e}\right)$. The distinction between notional and installed capital reflects problems in the public investment process. Public investment $i_{z}$ produces additional units of notional infrastructure $z$ according to:

$$
(1+g) z_{t}=(1-\delta) z_{t-1}+i_{z, t}
$$

but with corruption and/or other inefficiencies the capital actually installed in the economy evolves according to :

$$
z_{t}^{i}=\bar{s} \bar{z}+s\left(z_{t}-\bar{z}\right)
$$

where $\bar{s}, s \in[0,1]$ are parameters of efficiency at and off steady state, and $\bar{z}$ is the notional public capital at the (initial) steady state. Assuming inefficiencies in capital formation, one unit of additional notional capital investment generates $s \leq 1$ units of installed capital. Combining equations (7.17) and (7.18) yields the following equation of motion for installed capital:

$$
(1+g) z_{t}^{i}=(1-\delta) z_{t-1}^{i}+s\left(i_{z, t}-\overline{i_{z}}\right)+\bar{s} \overline{i_{z}}
$$

In addition to inefficiencies in construction we allow for additional adjustment costs associated with increasing public investment. These are costs, such as the additional costs of coordination or the pure costs of corruption (i.e. corruption is not a transfer) that drive a wedge between the cost of acquiring infrastructure in the market and the final cost to government; this wedge is increasing in the extent to which public investment exceeds its steady state value. We follow Buffie et al (2012) in assuming that the marginal cost of public investment to the fiscal authorities is defined as $\Pi_{t} P_{z, t}$ where $P_{z, t}$ is the cost of public capital as defined in 7.3 and

$$
\Pi_{t}=\left(\left(i_{z, t}-\overline{i_{z}}\right) \cdot\left(1+\frac{i_{z, t}}{z_{t-1}}-\delta-g\right)^{\phi}+\overline{i_{z}}\right) / i_{z, t}
$$

Note that in the initial steady state, where $i_{z, t}=\overline{i_{z}}$ so that $\frac{\overline{i_{z}}}{z_{t-1}}=\delta+g, \Pi_{t}=1$. Hence the adjustment costs accrue only on marginal public investment.

\subsubsection{Operations and maintenance expenditures}

Operations and maintenance expenditures affect public capital through two channels in the model. On the one hand, deficient maintenance expenditure leads to an increase in the rate at which the public capital stock depreciates through time. On the other, deficient operations expenditure reduces the flow of output produced by the current stock of public capital. Both 
effects can be temporary so that a return to 'full' maintenance and operations expenditures restores the (technical minimum) depreciation rate and the full flow of output respectively ${ }^{20}$

To operationalize these ideas we assume that installed public capital depreciates at a rate determined by the level of maintenance expenditure. The depreciation rate of (installed) public capital is defined as

$$
\delta_{z}^{i}=\delta_{z}\left[1+\left(1-\gamma_{m}\right) \beta_{\delta}\right]
$$

where $0<\gamma_{m} \leq 1$ is the ratio of actual to efficient maintenance expenditure and $\beta_{\delta} \geq$ 0 is a measure of excess depreciation. Thus the rate of depreciation is bounded between $\delta_{z}$ when maintenance is at its efficient level and $\delta_{z}\left(1+\beta_{\delta}\right)$ when maintenance is neglected entirely. The accelerated loss of installed capital during a period when maintenance is inadequate is permanent; however, if maintenance expenditure is subsequently improved, following such an episode, the depreciation rate on the remaining capital falls back to a lower level.

Finally, effective capital is defined as $z^{e}=\gamma_{p} z^{i}$ where $0<\gamma_{p} \leq 1$ is the ratio of actual to efficient operations expenditure. For simplicity, these operations and maintenance requirements are treated as being kinked at the efficient level; while there is an immediate loss involved when either $\gamma$ is allowed to fall below 1 , there is no corresponding gain if either is set greater than 1 . Such excess expenditure would just be wasted.

Both operations and maintenance expenditures are modeled as the use of traded and non traded goods, where we assume that the composition of traded and non-traded goods is fixed and is the same as the initial composition of domestic absorption. The composite price of O\&M is $P_{o m, t}=\left(1-a_{n}\right) P_{x, t}+a_{n} P_{n, t}$ where $a_{n}$ is the non-tradable share in absorption, so that an increase in the level of O\&M as a share of total absorption leaves the initial price vectors undisturbed. The quantities of this composite good are then defined respectively as $q_{p, t} z_{t-1}^{i}$ and $q_{m, t} z_{t-1}^{i}$ where $q_{p, t}=\gamma_{p, t} \bar{q}_{p}$ and $q_{m, t}=\gamma_{m, t} \bar{q}_{m}$ with $\overline{q_{p}}$ and $\overline{q_{m}}$ measures of 'efficient' O\&M goods expenditures per unit of installed capital ${ }^{21}$

Estimates of the scale of 'efficient' O\&M costs are extremely sparse. In this model we calibrate to values that are broadly consistent with Heller's (1991) 'r-coefficient' estimates. These are estimates of the required annual recurrent expenditure in dollars per dollar of installed capital (see Heller, 1991). His estimates are, however, highly dependent on the type of public capital involved, with the coefficients covering a huge range between $1 \%$ and $72 \%$; the lower values are characteristic of economic infrastructure, the higher ones of social infrastructure. Concentrating on maintenance only, for economic infrastructure, Fay and Yepes (2003) estimate values of 2\% for electricity generation, rail and road; $3 \%$ for water and sanitation; and $8 \%$ for mobile and

\footnotetext{
${ }^{20}$ This is a simplifying assumption: in practice, the capital stock may be so degraded as a result of deficient maintenance expenditures that it is simply not possible to restore it to 'full' efficiency without rebuilding afresh.

${ }^{21}$ It might seem natural to consider operations expenditures as intermediate goods, necessary in providing the final services of public capital. However, the present model is a pure value-added model, with no provision for intermediates; and since conventional national accounting tends to value these activities at cost we treat them as part of GDP.
} 
landline telephones. They stress that these are estimates of the minimum expenditure to ensure the integrity of the system, not of the higher levels that would be efficient. Even so, these magnitudes imply that required expenditures on maintenance of existing capital are typically slightly larger than expenditures on new investment.

We are aware of no quantitative evidence on the scale of the losses inflicted by inadequate O\&M, so the assumptions made here are necessarily speculative. However, we believe that these are quite conservative. In the simulations reported below, the measure of excess depreciation, $\beta$, is set equal to one. This implies that the depreciation rate would only double, for example from $5 \%$ to $10 \%$, even if maintenance were abandoned entirely. As regards operational expenditures, our proportionality assumption again seems on the conservative side.22

Importantly, it is not assumed that the prior or indeed final equilibrium of the economy is characterized by efficient O\&M. As a consequence of inadequate budget planning and implementation, exacerbated by the separation of responsibilities for investment decisions and for O\&M, there often is a substantial deficit in the latter from efficient levels. ${ }^{23}$ The problem may of course be temporarily worsened during an investment surge if that leads to fiscal difficulties; on the other hand, a program of reforms to public financial management may yield a sustained improvement in the relationship. The present model is designed to permit all these possibilities to be explored.

Adding in depreciation and debt-financing costs the full cost of public investment is given as

$$
\left[P_{o m, t}\left(q_{p, t}+q_{m, t}\right)+\left(\delta_{z, t}^{i}+r_{t}^{g}\right) P_{z, t} / s\right] z_{t-1}^{i}
$$

The first two terms are the recurrent cash costs of operations and maintenance; the third and fourth terms correspond to the depreciation and financing costs per unit of installed capital, where $r_{t}^{g}$ is the marginal cost of government (non-concessional) borrowing, recognizing that a unit of installed capital costs $P_{z} / s$ to replace 24

Finally, we define the user-cost recovery rate as:

$$
\mu_{t}=\left[P_{o m, t}\left(f_{p, t} q_{p, t}+f_{m, t} q_{m, t}\right)+\left(f_{d, t} \delta_{z, t}^{i}+f_{r, t} r_{t}\right) P_{z, t} / s\right] z_{t-1}^{i}
$$

\footnotetext{
${ }^{22}$ In practice, operations expenditures tend to be composites, the components of which are likely to be required in fixed proportions. Since inadequate spending is itself inefficient, it seems most unlikely that the reduction would be allocated optimally between these components. For example, a health clinic may receive inadequate supplies of medicines, even when it is adequately staffed with medical personnel. This is likely to reduce services more than proportionally to the reduction in the operational budget. It would be straightforward to model this relationship by treating operations as a Leontief relationship between labor inputs and goods expenditures.

${ }^{23}$ Rioja (2003) "Filling potholes: macroeconomic effects of maintenance versus new investments in public infrastructure" Journal of Public Economics, models the issue, and suggests that it would often be efficient to divert available finance from new investment to increased maintenance of the existing stock. There appears to be less hard numerical evidence in respect of operations expenditures, but anecdotal evidence as to its common inadequacy abounds.

${ }^{24}$ The rationale for treating the financing cost as equivalent to the cost of borrowing is discussed in Appendix II of Adam and Bevan (2014).
} 
where $0<f_{n} \leq 1$ for $n=p, m, d, r$ are the recovery rates for each financing component. The reason for distinguishing these rates is that the financing components have very different perceptual properties, and are most unlikely to be treated as an aggregate in budget decisions. In the calculations reported below, it is assumed that there may be some cost recovery (on an equal basis) for O\&M expenditure, but not for the other two categories of cost. That reflects the likely budget operations in many public finance systems.

\subsubsection{Tax leakage}

To allow for inefficiencies or corruption or other forms of leakage in revenue collection we introduce a wedge which determines what proportion of the tax levied on a particular base actually finds its way onto the government budget. We define $0<t_{s} \leq 1$ as the share of the tax collected on tax base $s$ that is remitted to government with $\left(1-t_{s}\right)$ of the revenue retained by the owner of the tax base. Crucially, firms and households always face the nominal tax rates when making choices over factor allocations and consumption decisions: tax revenues that are 'retained' are treated as if they were lump-sum transfers from government. What this means is that when $t_{s}<1$ a given given government revenue requirement entails a structure of nominal tax rates that is higher and thus more distortionary that in the absence of any leakages.

\subsubsection{Public sector budget constraint}

Combining these elements we derive the government's budget constraint. The government spends on debt service, infrastructure investment, associated operations and maintenance, and transfers to the private sector. It collects tax revenue from consumption taxes and from taxes on capital and labor, in all cases net of 'leakages' to the private sector. Additional revenue accrues from grants from development partners, and from user fees for infrastructure services. When revenues fall short of expenditures, the resulting deficit is financed through domestic borrowing $\Delta b_{t}=$ $b_{t}-b_{t-1}$, external concessional borrowing $\Delta d_{t}=d_{t}-d_{t-1}$, external commercial borrowing $\Delta d_{c, t}=d_{c, t}-d_{c, t-1}$, or by drawing down net international reserves $\Delta n i r_{t}=n i r_{t}-n i r_{t-1}$. Hence:

$$
\begin{gathered}
\Delta b_{t}+\Delta d_{c, t}+\Delta d_{t}-\Delta n i r_{t}=\frac{r_{t-1}-g}{1+g} b_{t-1}+\frac{r_{d, t-1}-g}{1+g} d_{t-1}+\frac{r_{d c, t-1}-g}{1+g} d_{c, t-1}+P_{z, t} \Pi_{t} i_{z, t} \\
+P_{o m, t}\left(q_{m . t}+q_{p, t}\right) z_{t-1}^{i}+T_{t}+d T_{t}-\frac{r_{f}-g}{1+g} n i r_{t-1} \\
-\sum_{j} t_{j} \theta_{j, t} r_{j, t} k_{j, t-1}^{s}-t_{w} \theta_{w, t} w_{t}\left(L_{n, t}+L_{x, t}\right)-\sum_{l} t_{c l} h_{l, t} P_{l, t} c_{l t}-G_{t}-\mu z_{t-1}^{i}
\end{gathered}
$$

for $j=x, n$ and $l=x, m, n$ where $G$ denotes grants. The world risk free rate is $r_{f}$, the interest rate on concessional loans is assumed to be constant $r_{d, t}=r_{d}$, while the interest rate on external commercial debt incorporates a risk premium that depends on the deviations of the 
external public debt to GDP ratio $e d_{t}=\frac{d_{t}+d_{c, t}-n i r_{t}}{y_{t}}$ from its (initial) steady state value where $y_{t}=P_{x, t} q_{x, t}+P_{n . t} q_{n, t}$ is GDP. That is,

$$
r_{d c, t}=r_{f}+v_{g} e^{\eta_{g}\left(e d_{t}-\bar{e} d\right)} .
$$

If $v_{g}>0$ and $\eta_{g}=0$, this specification provides for an exogenous risk premium that does not depend on the level of public debt; if both are positive, the premium is increasing in the external debt to GDP ratio.

\subsection{Fiscal adjustment and policy rules}

Given the exogenously determined paths for public infrastructure investment, concessional and non-concessional sovereign external borrowing, and the sovereign wealth fund, the residual fiscal adjustment falls on domestic taxes and domestic debt. To illustrate, we start with a measure of the fiscal gap before adjustment $\left(\Omega_{t}\right)$ :

$$
\begin{aligned}
\Omega_{t}=P_{z, t} \Pi_{t} i_{z, t}+ & P_{o m, t}\left(q_{p, t}+q_{m, t}\right) z_{t-1}^{i}++T_{t}+d T_{t}+\frac{1+r_{d}}{1+g} d_{t-1}-d_{t}+\frac{1-r_{d c, t-1}}{1+g} d c_{t-1} \\
& -d c_{t}+\frac{r_{t-1}-g}{1+g} b_{t-1}-\frac{r_{f}-g}{1+g} n i r_{t-1}-\sum_{j} t_{j} \theta_{j 0} r_{j, t} k_{j, t-1}^{s} \\
& -t_{w} \theta_{w 0} w_{t}\left(L_{n, t}+L_{x, t}\right)-\sum_{l} t_{c l} h_{l 0} P_{l, t} c_{l t}-G_{t}-\mu z_{t-1}^{i} .
\end{aligned}
$$

$\Omega_{t}$ corresponds to expenditures (including interest payments) less revenues and concessional borrowing, when taxes are kept at their initial levels $\left\{\theta_{x 0}, \theta_{n 0}, \theta_{w 0}, h_{c x 0}, h_{c m 0}, h_{c n 0}\right\}$. Using this definition, the government budget constraint (7.24 can be rewritten as:

$$
\Omega_{t}=\Delta b_{t}+\sum_{l} t_{c l}\left(h_{l, t}-h_{l 0}\right) P_{l, t} c_{l, t}+\sum_{j} t_{j}\left(\theta_{j, t}-\theta_{j 0}\right) r_{j, t} k_{j, t-1}^{s}+t_{w}\left(\theta_{l, t}-\theta_{l 0}\right) w_{t}\left(L_{n, t}+L_{x, t}\right)
$$

In other words, given the investment program, this gap can be covered by some mixture of domestic borrowing and tax adjustments. Debt sustainability necessarily requires that domestic debt is bounded (for example, we may assume that the domestic debt is constrained to converge to a constant share of trend GDP) which means that taxes eventually adjust to cover the entire gap, conditional on the long-run domestic debt ratio. Policymakers divide the long-run burden of adjustment across different taxes as follows:

$$
\begin{array}{cc}
h_{l t}^{\text {target }}=t_{c l} h_{l 0}+\lambda_{h l} \frac{\Omega_{t}}{P_{l, t} c_{l, t}} & l=\{x, m, n\} \\
\theta_{j t}^{\text {target }}=t_{j} \theta_{j 0}+\lambda_{k j} \frac{\Omega_{t}}{r_{j, t} k_{j, t}} \quad j=\{x, n\}
\end{array}
$$




$$
\theta_{w t}^{\text {target }}=t_{w} \theta_{w 0}+\lambda_{w} \frac{\Omega_{t}}{w_{t}\left(L_{n, t}+L_{x, t}\right)}
$$

where $0 \leq \lambda_{h l}, \lambda_{k j}, \lambda_{w} \leq 1$ are policy parameters that split the long-run fiscal adjustment between different taxes and domestic debt. When $\sum \lambda=1$ domestic debt is held constant (as a share of trend GDP) in the long run. When $\sum \lambda<1$ the new steady-state entails a rise in the domestic debt ratio and vice versa when $\sum \lambda>1$.

Finally, we assume that taxes cannot adjust instantaneously to their new target levels so that over the adjustment path domestic debt may overshoot its steady-state level. The actual path for taxes is defined as follows (with the evolution of domestic debt determined implicitly from the substitution of these dynamic equation into the government budget constraint (7.24):

$$
\begin{gathered}
t_{c l, t} h_{l, t}=t_{c l, t-1} h_{l, t-1}+\lambda_{h 1}^{d}\left(h_{l t}^{\text {target }}-t_{c l, t-1} h_{l, t-1}\right) \quad l=\{x, m, n\} \\
t_{j, t} \theta_{j, t}=t_{j, t-1} \theta_{j, t-1}+\lambda_{k j}^{d}\left(\theta_{j t}^{\text {target }}-t_{j, t-1} \theta_{j, t-1}\right) \quad j=\{x, n\} \\
t_{w, t} \theta_{w, t}=t_{w, t-1} \theta_{w, t-1}+\lambda_{w}^{d}\left(\theta_{w t}^{\text {target }}-t_{w, t-1} \theta_{w, t-1}\right)
\end{gathered}
$$

with $\lambda_{h 1}^{d}, \lambda_{k j}^{d}, \lambda_{w}^{d}>0$.

\subsection{Market-clearing conditions}

Flexible wages and prices ensure that demand continuously equals supply in the labor market:

$$
L_{x, t}+L_{n, t}=L_{t}^{h}+L_{t}^{s} .
$$

Aggregating over both types of consumers, and taking into account private and public investment and O\&M expenditures, equilibrium in the non-tradable sector is:

$$
q_{n, t}=\rho_{n}\left(\frac{P_{n, t}}{P_{t}}\right)^{-\epsilon} c_{t}+a_{k}\left(i_{x, t}+i_{n, t}\right)+a_{z} \Pi_{t} i_{z, t}+a_{n}\left(q_{m, t}+q_{p, t}\right) z_{t}^{i} .
$$

Finally, consolidating public and private sector budget constraints yields the accounting identity that growth in the country's foreign debt net of the sovereign wealth fund equals the difference between national spending and national income:

$$
\begin{gathered}
\Delta d_{t}+\Delta d_{c, t}-\Delta n i r_{t}=\frac{r_{d}-g}{1+g} d_{t-1}+\frac{r_{d c, t-1}-g}{1+g} d_{c, t-1}-\frac{r_{f}-g}{1+g} n i r_{t-1}+P_{z, t} \Pi_{t} i_{z, t} \\
+P_{k, t}\left(i_{x, t}+i_{n, t}\right)+P_{o m, t}\left(q_{p, t}+q_{m, t}\right)+P_{t} c_{t}-P_{n, t} q_{n, t}-P_{x, t} q_{x, t}-R_{t}-G_{t}
\end{gathered}
$$



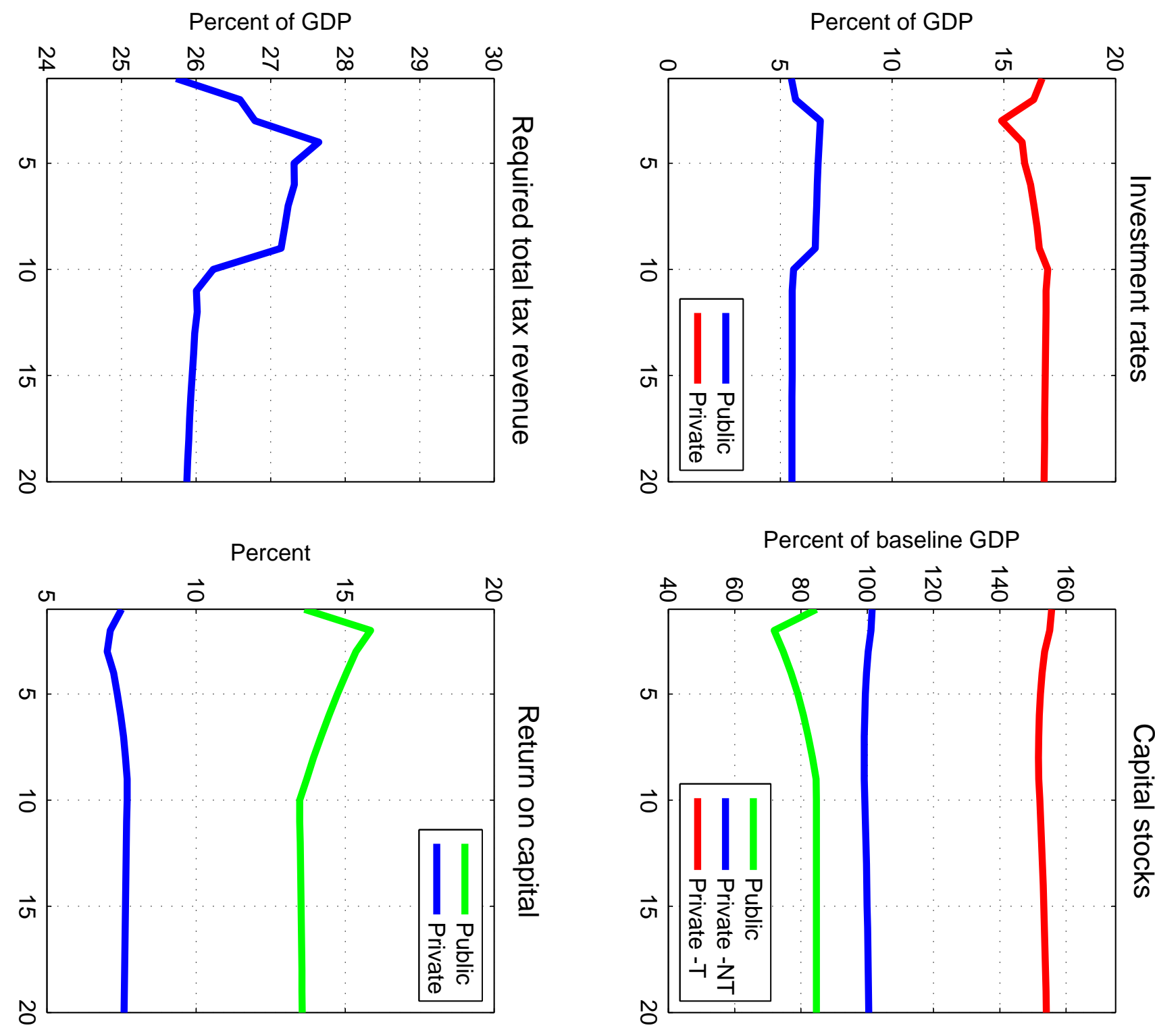

Percent of baseline GDP
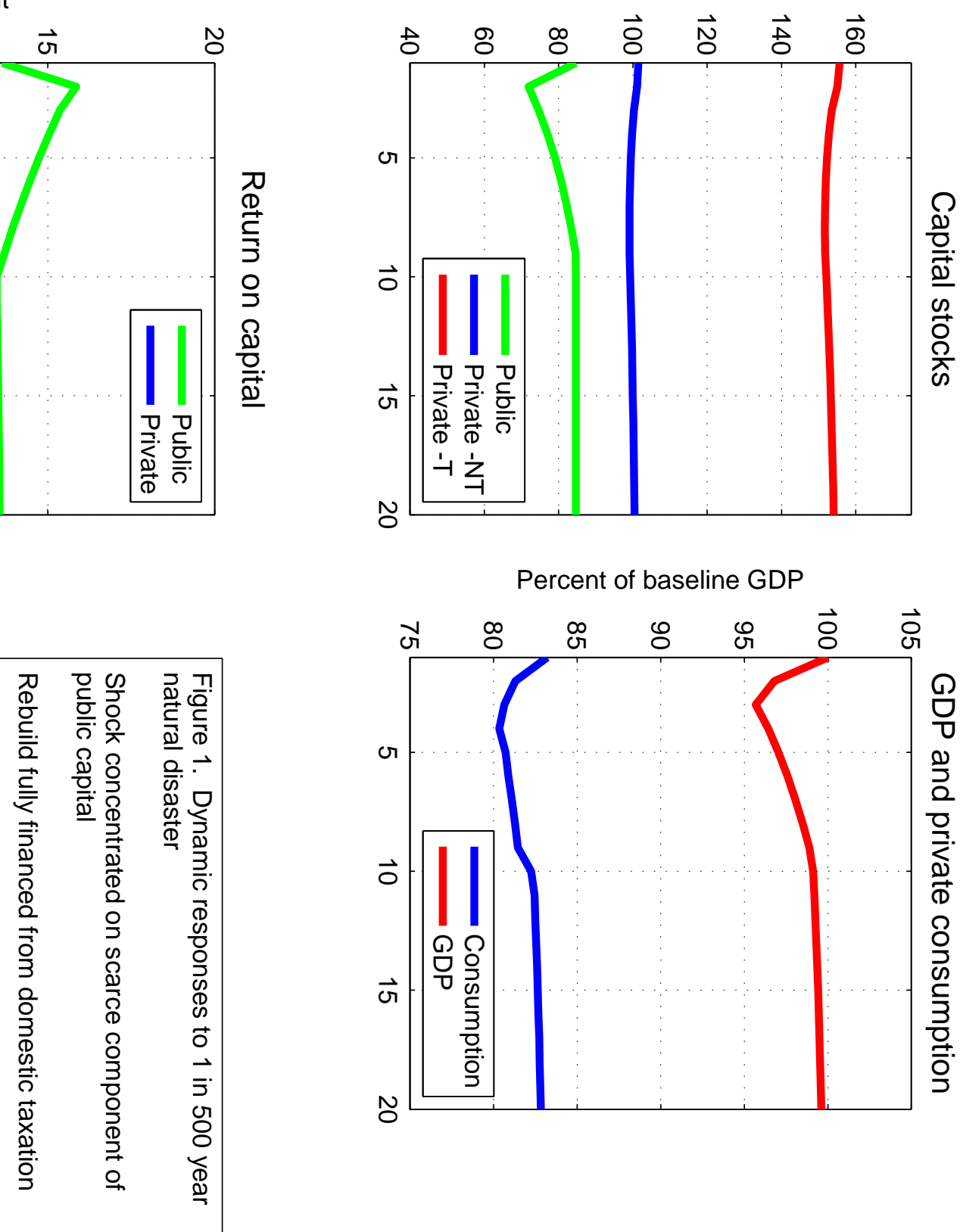


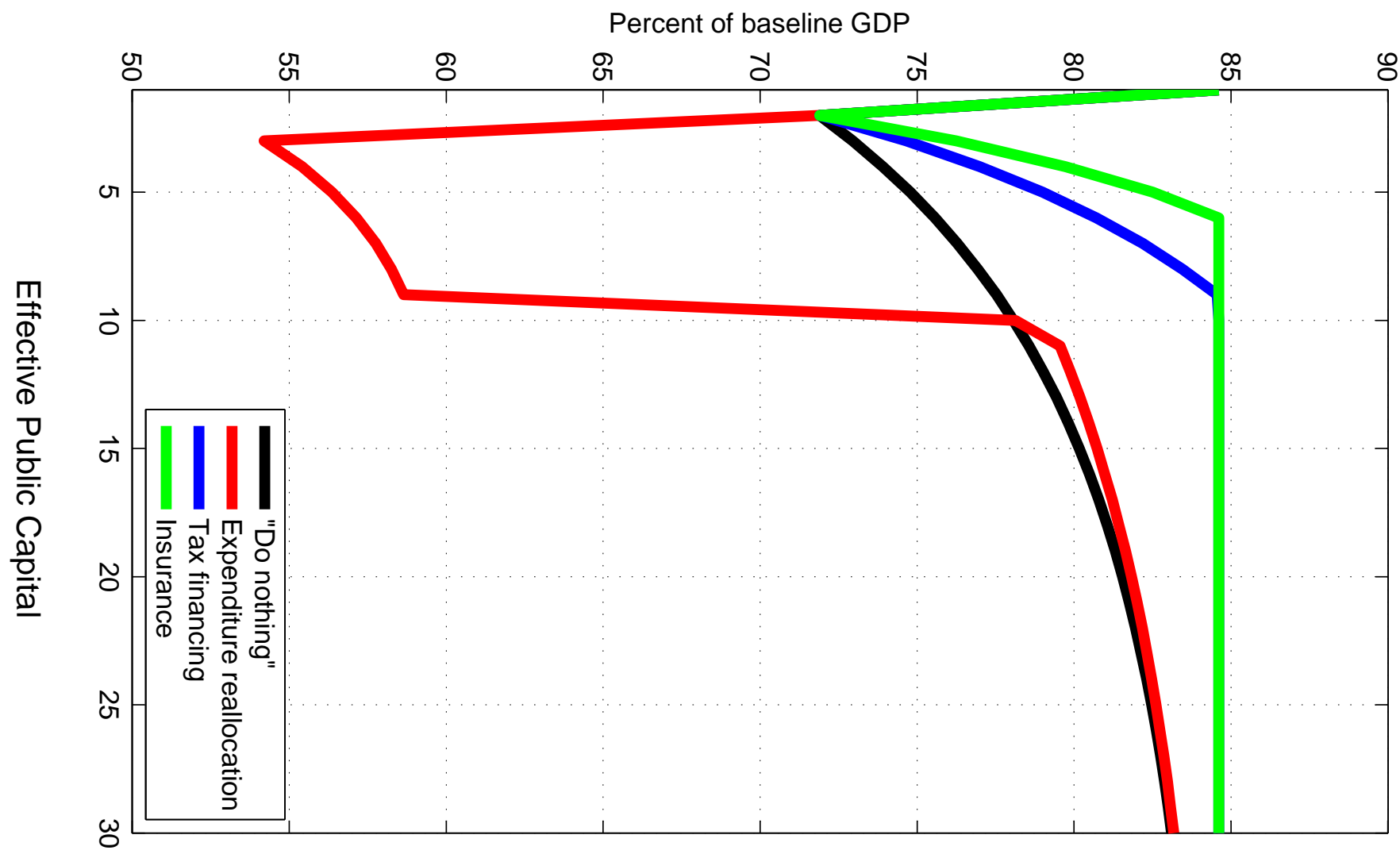

$\varnothing$

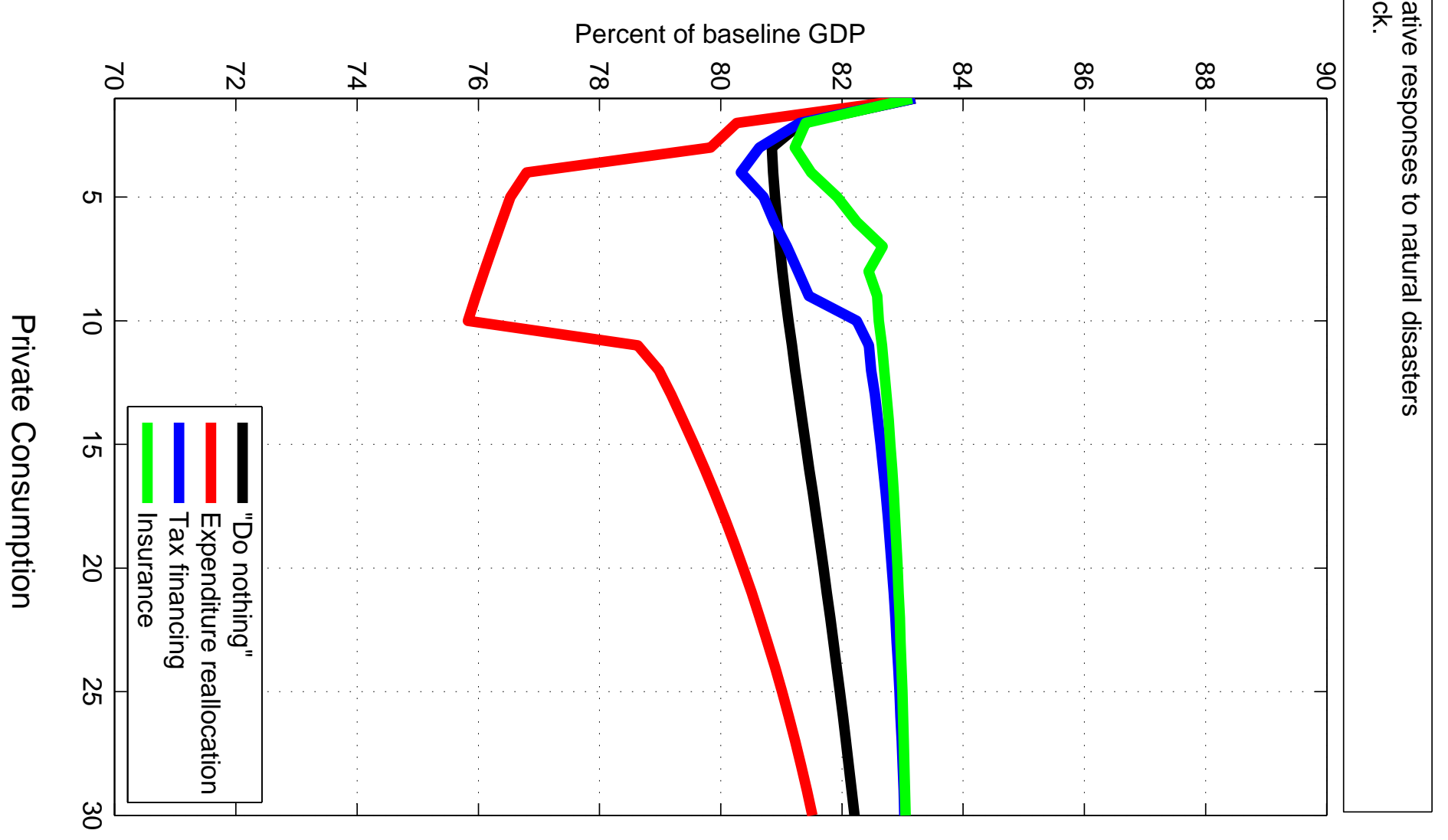




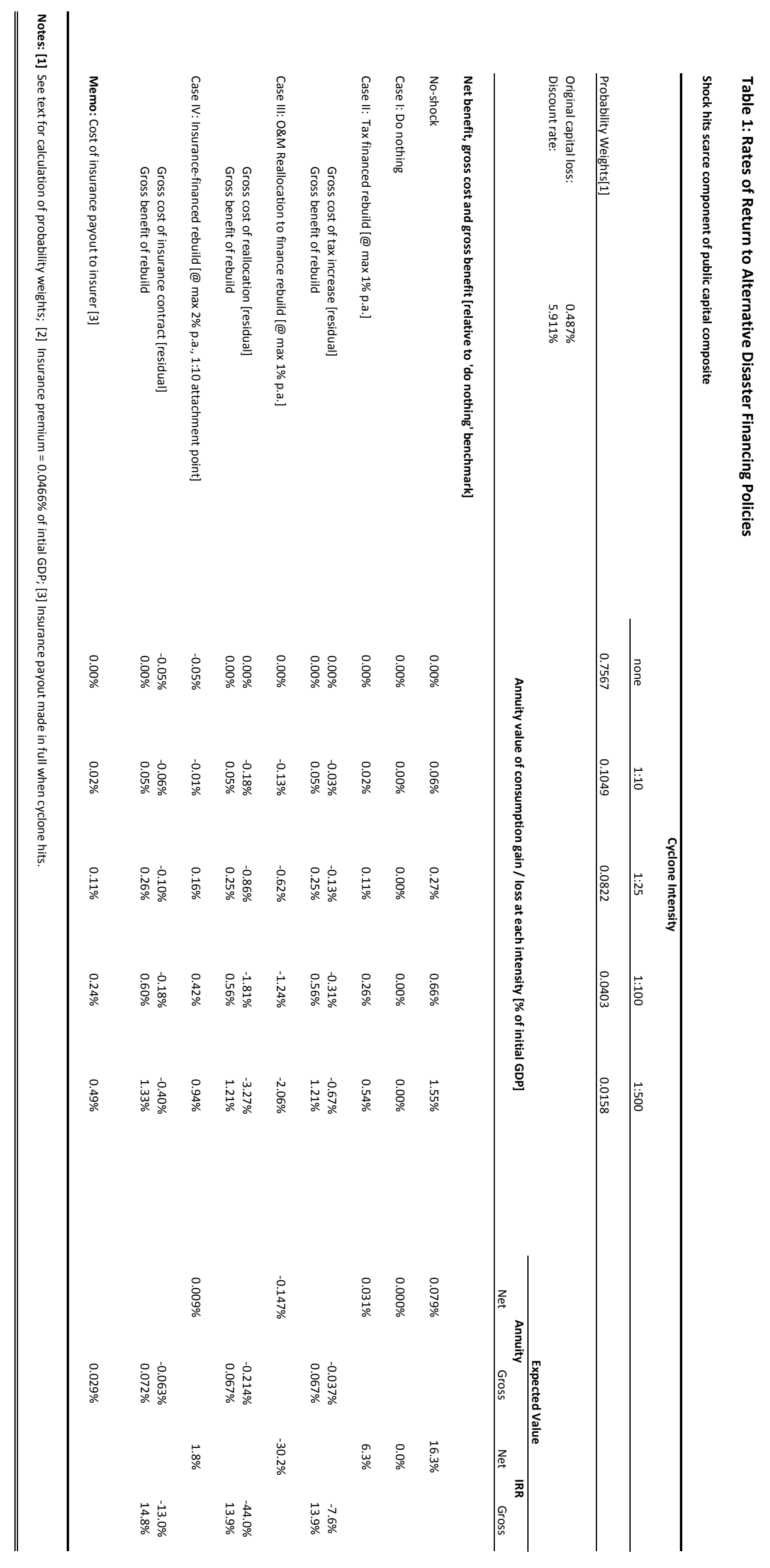




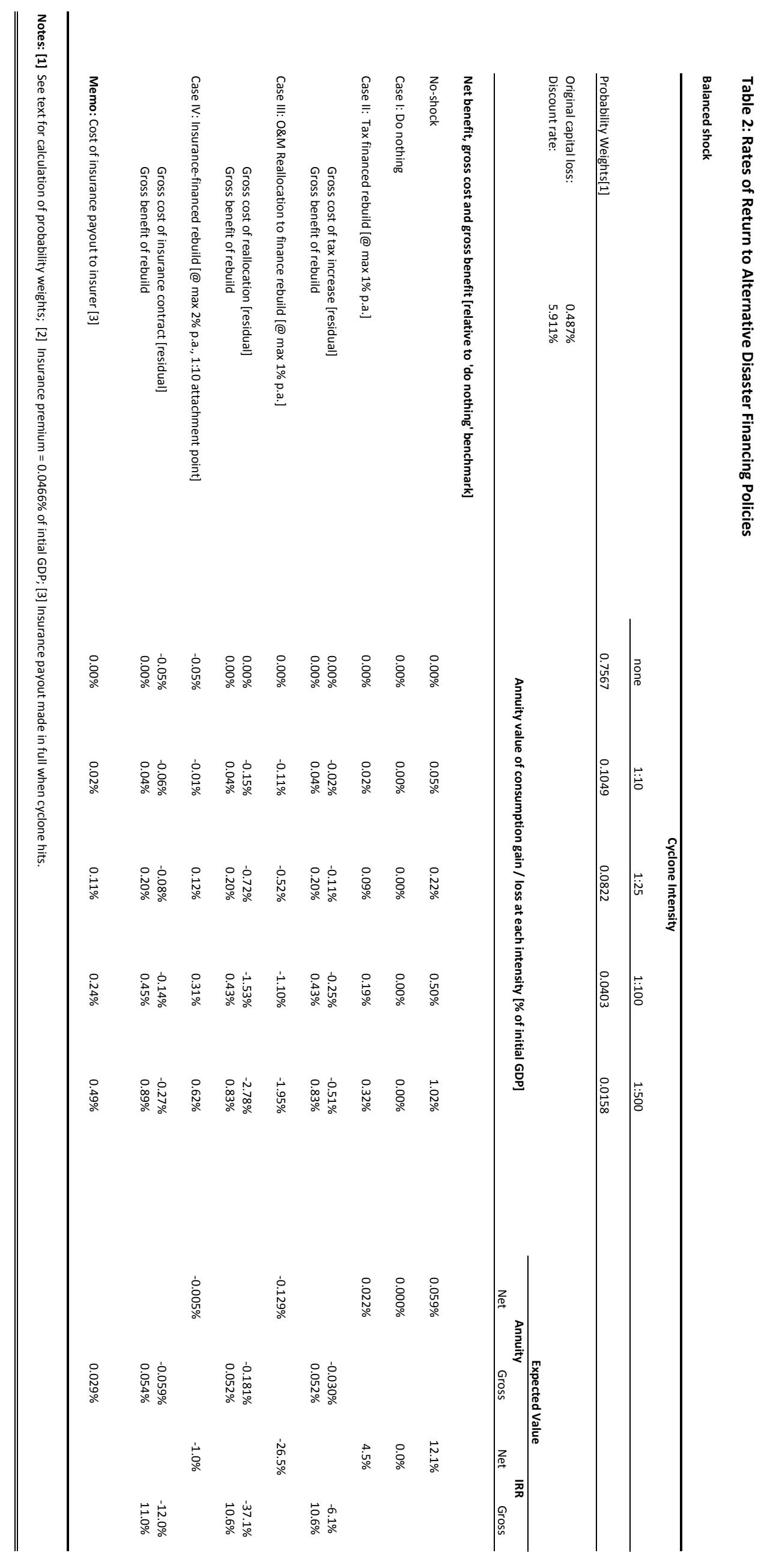




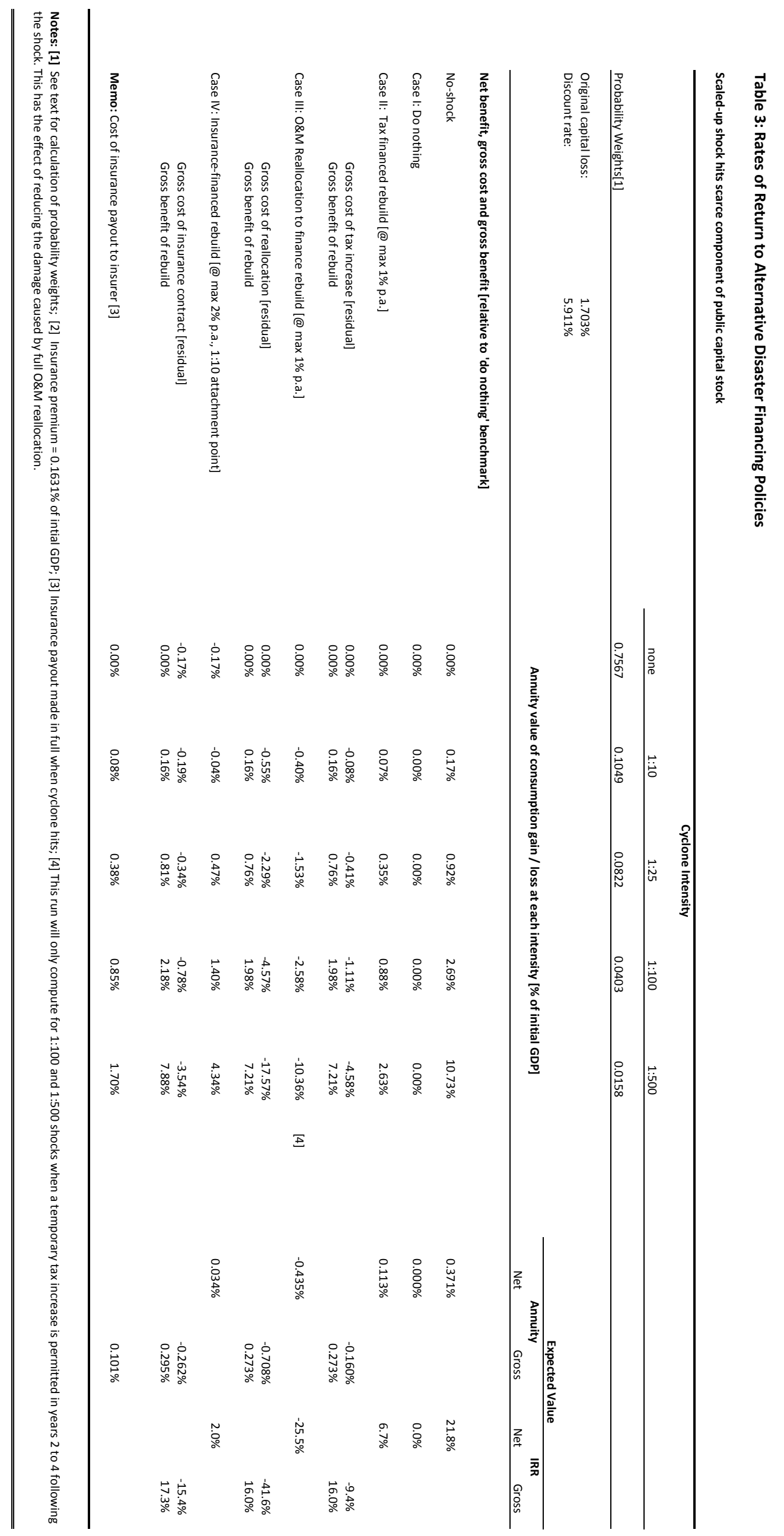




\section{Appendix Table I}

Elasticity of steady state output with respect to public capital stock

\begin{tabular}{|c|c|c|c|c|c|}
\hline \multirow[t]{2}{*}{$\begin{array}{c}\text { Composition of } \\
\text { public capital (z1:z2) } \\
{[1]}\end{array}$} & \multirow[t]{2}{*}{$\begin{array}{c}\text { Elasticity of } \\
\text { Substitution }\end{array}$} & \multirow[t]{2}{*}{ Threshold $^{[3]}$} & \multirow[t]{2}{*}{ Incidence $^{[4]}$} & \multicolumn{2}{|c|}{$\begin{array}{l}\text { Elasticity with respect to change in } \\
\text { installed capital }\end{array}$} \\
\hline & & & & Public capital & GDP \\
\hline $50: 50$ & 1000 & 0 & Balanced & 1.00 & 0.27 \\
\hline $50: 50$ & 1000 & 0.25 & Balanced & 1.00 & 0.37 \\
\hline $50: 50$ & 0.25 & 0 & Balanced & 1.00 & 0.27 \\
\hline $50: 50$ & 0.25 & 0.25 & Balanced & 1.00 & 0.37 \\
\hline $40: 60$ & 1000 & 0 & Balanced & 1.00 & 0.27 \\
\hline $40: 60$ & 1000 & 0 & $z 1$ & 1.00 & 0.27 \\
\hline $40: 60$ & 1000 & 0 & $\mathrm{z2}$ & 1.00 & 0.27 \\
\hline $40: 60$ & 1000 & 0.25 & Balanced & 1.00 & 0.37 \\
\hline $40: 60$ & 1000 & 0.25 & $\mathrm{z1}$ & 1.00 & 0.37 \\
\hline $40: 60$ & 1000 & 0.25 & $\mathrm{z2}$ & 1.00 & 0.37 \\
\hline $40: 60$ & 0.25 & 0 & Balanced & 1.00 & 0.27 \\
\hline $40: 60$ & 0.25 & 0 & $\mathrm{z} 1$ & 2.02 & 0.62 \\
\hline $40: 60$ & 0.25 & 0 & $\mathrm{zz}$ & 1.35 & 0.38 \\
\hline $40: 60$ & 0.25 & 0.25 & Balanced & 1.00 & 0.37 \\
\hline $40: 60$ & 0.25 & 0.25 & $\mathrm{z1}$ & 2.02 & 0.95 \\
\hline $40: 60$ & 0.25 & 0.25 & $z 2$ & 1.35 & 0.54 \\
\hline
\end{tabular}

Notes: [1] Composition of initial aggregate public capital stock between components z1 and z2; [2] elasticity of substitution between components of composite public capital; [3] threshold in public capital above which installed public capital becomes effective; [4] incidence of shock to components of composite public capital. See text for details. 
Appendix Table II

Jamaica: Baseline Calibration [2012/13]

(as \% of GDP at factor cost)

\begin{tabular}{|c|c|c|c|}
\hline GDP & 100.00 & Balance of Trade & -9.64 \\
\hline Tradable & 53.50 & Interest on Debt & 3.89 \\
\hline \multirow[t]{2}{*}{ Non-Tradable } & 46.50 & Current Account & -13.53 \\
\hline & & Financing: & \\
\hline \multirow[t]{2}{*}{ Absorption } & 109.64 & Aid & 2.50 \\
\hline & & Remittances & 10.00 \\
\hline Consumption & 83.20 & Debt financing & 1.03 \\
\hline Tradable & 49.92 & Debt Stocks & 120.00 \\
\hline \multirow[t]{2}{*}{ Non-tradable } & 33.28 & Concessional & 36.00 \\
\hline & & Non-Concessional & 34.00 \\
\hline Investment & 22.21 & Domestic & 50.00 \\
\hline Private & 16.71 & Fiscal Balance & \\
\hline \multirow[t]{2}{*}{ Public } & 5.50 & Revenue & 25.73 \\
\hline & & Cons & 16.64 \\
\hline \multirow[t]{2}{*}{ Government } & 24.51 & Labour & 5.88 \\
\hline & & Capital & 3.21 \\
\hline O\&M & 4.23 & & \\
\hline Transfers & 12.69 & Expenditures & 30.01 \\
\hline \multirow{5}{*}{ Interest } & 7.59 & & \\
\hline & & Deficit & -4.28 \\
\hline & & Financing: & \\
\hline & & Grants & 2.50 \\
\hline & & Debt & 1.78 \\
\hline
\end{tabular}

Sources: Statistical Institute of Jamaica; IMF 